\title{
COMPARATIVE ORCHIDOTOXICITY STUDY BETWEEN CHLOROQUINE PHOSPHATE AND HYDROXYCHLOROQUINE SULFATE ON ADULT ALBINO RATS
}

\author{
Ibrahim S. Elgndy, Ibrahim S. Zamzam, Mohamed F. Khodeary, Maha M. Mokhtar \\ Department of Forensic Medicine and Clinical Toxicology, Faculty of Medicine, Benha \\ University
}

\begin{abstract}
Introduction: Chloroquine phosphate (CQP) and hydroxychloroquine sulfate (HCS) are antimalarial drugs commonly used for treatment of malaria and numerous rheumatic diseases. Their widespread prescriptions may accompany with prolonged duration of therapy and higher daily dosages, leading to several toxic effects, including disturbance of reproductive system. Aim of the study: The present study was designed to compare the effect of six-week exposure to CQP and HCS on reproductive function of adult male albino rats. Materials and Methods: The study was conducted on 30 normal adult male albino rats divided equally into 3 groups (10 rats each), the Control-group (C-group) was given $1 \mathrm{ml}$ of distilled water orally, whereas the CQPgroup (62 mg/kg/b. wt. ) and HCS-group (124 mg/kg/b. wt. ) were given single daily oral doses equivalent to $1 / 10^{\text {th }}$ of $\mathrm{LD}_{50}$ of each drug for 6 consecutive weeks then all animals sacrificed. The serum levels of testosterone, luteinizing hormone (LH), and follicle stimulating hormone (FSH), quality of epididymal sperm (count, motility, viability, and morphology), degeneration severity of seminiferous tubules (SNT) and Leydig cells count per each animal, semi-quantitative scoring of SNT and Leydig cells histopathological changes, spermatogenesis maturity levels, and structural and ultrastructural morphologies of tissues were estimated. Results: The CQP-group showed severe orchidotoxic effects as manifested by statistically significant reductions in final weight gains of body, testes, and epididymis, all sperm quality, and all hormone levels, marked increases in the number of animals associated with SNT degeneration and reduced Leydig cells count, statistically significant increases in abnormalities of SNT and Leydig cells architectures, statistically significant decrease of spermatogenesis maturity levels, and extensive structural and ultrastructural changes in testicular parenchyma and interstitial tissues as compared to C-group and HCS-group. While, HCS-group displayed minor orchidotoxic effects as evidenced by insignificant changes in most of the evaluated parameters, significant reductions of LH and FSH levels, slight increases in the number of animals accompanied with SNT degeneration and reduced Leydig cells count, and minor changes of structural and ultrastructural testicular tissue architectures as compared to C-group. Conclusion, these results suggest that $\mathrm{CQP}$ has more orchidotoxic effects than HCS, and in terms of therapeutic usage, physicians should better prescribe HCS as it appears safer than CQP. Also, assessment of male reproductive functions should be done periodically for patients receiving both drugs for prolonged time, especially CQP, as they may induce endocrine disruptions.
\end{abstract}

Keywords: chloroquine Phosphate, hydroxychloroquine sulfate, male reproductive system, spermatogenesis, testicular toxicity, orchidotoxic effects. 


\section{INTRODUCTION}

Chloroquinephosphate (CQP) and its synthetic analogue, hydroxychloroquine sulfate (HCS), are 4-aminoquinoline derivative compounds commonly used in the treatment of several diseases (Taherian et al., 2013). The CQP was first synthesized in 1934 by Hans Andersag and co-workers at Bayer Company in Germany under the name Resochin, while HCS was synthesized in 1946 by Alexander Surrey and Henry Hammer through addition of the hydroxy group to the parent compound chloroquine (McChesney, 1983).

Both drugs share a common similarity in their therapeutic aspects (Pasadhika and Fishman, 2010). In addition to their initial use as antimalarial compounds, both medications possess immunosuppressive actions and have been employed in the treatment of various rheumatological diseases such as rheumatoid arthritis and systemic lupus erythematosus, and other dermatologic conditions and connective tissue disorders for many decades (Taherian et al., 2013). However, in most parts of the world, HCS has broadly replaced CQP because of its better tolerability at high dosages (Pasadhika and Fishman, 2010).

The pharmacokinetics and pharmacodynamics properties of these two drugs are very similar (Pile et al., 2016).

The mechanisms of action of 4aminoquinoline derivative antimalarial drugs are still not fully understood. However, these compounds may interfere with ferriprotoporphyrin IX (FP) detoxification by making unsaturated lipids unavailable for the promotion of FP dimerization (FP is an intermediary product produced when the malarial parasites digest or consume hemoglobin as a source of amino acids for its own protein synthesis), remove FP from oxidized hemoglobin, bind to FP producing toxic complexes, impair endosomal maturation, and cause an excess of denaturated globin. The previous mechanisms may resulting in loss of potassium ions, an increase in the membrane permeability, and swelling leading to osmotic lysis of malariaparasitized erythrocytes and the protozoans themselves (Mackenzie, 1983; Fitch and Russell, 2006).

The modes of action of antimalarial preparations as disease modifying antirheumatic drugs are complex and have not been fully elucidated, but multiple pathways have been proposed including anti-inflammatory, anti-proliferative, immunomodulatory, and photoprotective effects (Rodriguez-Caruncho and BielsaMarsol, 2014). These drugs have the ability to accumulate in lysosomes and autophagosomes of phagocytic cells and protect against cytokine-mediated cartilage resorption as well as modulating the actions of pro-inflammatory cytokines production (e. g. interleukin-1, tumour necrosis factor- $\alpha$ ); major histocompatibility complex (MHC Class II) expression and antigen presentation; control of toll-like receptor- 9 activation; and leucocyte generation of reactive oxygen species (i. e. antioxidant activity) (Rainsford et al., 2015).

Although both drugs are generally well tolerated, their widespread and extensive prescriptions for treatment of patients with non-malarial diseases may result in prolonged duration of therapy and higher daily dosages leading to cumulative doses greater than those utilized in antimalarial therapy with subsequent occasional development of significant number of toxic effects (Pile et al., 2016).

Several authors have reported that both drugs share a similarity in their toxicological aspects (Pasadhika and Fishman, 2010) and the most commonly recorded adverse effects include neurotoxicity, cardiotoxicity, oculotoxicity, gastrointestinal and hepatorenal disorders, allergic reactions, and skin 
and hair lesions (Pile et al., 2016). However, Geamănu Pancă et al. (2014) stated that although these two drugs are structurally related, they have shown different therapeutic and toxic doses with HCS being less toxic than CQP.

Infertility is a growing global public health problem and a vast number of xenobiotic compounds can disrupt the functional diversity of the male reproductive system and interfere with the complexity of its hormonal regulation resulting in impairment of male fertility available for female fertilization (Creasy, 2001).

The gonadotoxic effects of different anti-inflammatory and immunosuppressive drugs, including CQP and HCS, have seldom been studied. However, there are increasing reports from experimental and preclinical animal studies that these drugs may impair male and female fertility (Østensen et al., 2006).

Several studies have shown that administration of synthetic (Quinacrine), semisynthetic (Artesunate), and plantderived (Quinine) antimalarial compounds can produce alterations in cellular function of the testes, hormonal balance, and the process of spermatozoa development, thus may potentially causing male infertility (Clewell et al., 2009; Izunya et al., 2010; Farombi et al., 2012).

Currently, there are few studies regarding the toxic effects of CQP on male reproductive function and morphology (Okanlawon et al., 1993; Adeeko and Dada, 1998; Asuquo et al., 2007). On the other hand, there arelimiteddataregarding the adverse effects of HCS on male reproductive system (Ostensen, 2006; Silva et al., 2010).

\section{AIM OF THE WORK}

In view of the aforementioned findings, the present experimental study was designed to compare the gonado-toxic effects of exposure to CQP and HCS for 6 weeks on adult male albino rats' reproductive function and morphology.

\section{MATERIALS \& METHODS}

Drugs: Chloroquine Phosphate (CQP; Alexoquine tablets contain $250 \mathrm{mg} /$ tablet) was obtained from Alexandria Company for Pharmaceutical and Chemical Industries (Alexandria, Egypt). Hydroxychloroquine Sulfate (HCS; Plaquenil tablets contain $200 \mathrm{mg} / \mathrm{tablet}$ ) was obtained from Sanofi-Aventis S. A. E. (Cairo, Egypt). The drugs were dissolved in distilled water (Tanenbaum and Tuffanelli, 1980). All other chemicals were of highest grade commercially available.

Animals

This study was carried out at the animal facility of Benha Faculty of Medicine after experimental protocol approval by the Ethics committee of Scientific Research, Faculty of medicine, Benha University, Egypt. The study comprised 30 adult male albino rats (Sprague Dawley strain, weighing 160180-gm at the start of the experiment, 7-8 weeks old; obtained from Helwan farm belonging to the Holding Company for Biological Products and Vaccines, VACSERA, Egypt). The animals were housed in cages (five rats per cage) and maintained under good hygienic and standard laboratory conditions of husbandry (12-hr light/dark cycles at $25 \pm$ $2{ }^{\circ} \mathrm{C}$ room temperature and 50-55\% relative humidity) with food and water ad libitum. The animals were subjected to a one week acclimatization period before the onset of the study in order to adapt themselves to their new environment, to ascertain their physical wellbeing, and to exclude diseased rats. All animal treatments adhered strictly to institutional and international ethical guidelines of the care and use of laboratory animals. 


\section{Experimental design}

The animals were randomly divided into three equal groups (10 rats per each group) and each fasted rat was subjected to treatment regimen orally via gastric gavage for 6 consecutive weeks as follows:

1- Control-group (C-group): The rats were given $1 \mathrm{ml}$ of distilled water.

2- Chloroquine phosphate-group (CQPgroup): The rats were treated with 62 $\mathrm{mg} / \mathrm{kg} / \mathrm{b}$. wt. solution of CQP (equivalent to $1 / 10^{\text {th }}$ of its oral $\mathrm{LD}_{50}$ in rats) (Walum, 1998).

3- Hydroxychloroquine sulphate-group (HCS-group): The rats were administered $124 \mathrm{mg} / \mathrm{kg} / \mathrm{b}$. wt. solution of HCS (equivalent to $1 / 10^{\text {th }}$ of its oral $\mathrm{LD}_{50}$ in rats) (MSDS, 2011).

Before each administration, a fresh solution was prepared in distilled water to obtain the necessary drug concentration in $1 \mathrm{ml}$. All rats were weighed before administration of their corresponding treatment regimen and the doses were calculated according to their daily weights.

\section{Collection of samples}

Twenty four hours after the end of the experimental period, the animals were weighed and anesthetized by diethyl ether inhalation and then subjected to thoracolaparotomy incision to obtain blood samples from the heart directly by needle aspiration and remove testes before they were sacrificed by decapitation.

Hormonal analysis: Blood samples were collected in clean tubes lacking anticoagulant and left at $37^{\circ} \mathrm{c}$ incubator for $15 \mathrm{~min}$ to coagulate. Coagulated blood samples were centrifuged for $15 \mathrm{~min}$ at 3000 revolutions per minute. The clear non-haemolysed supernatant sera were quickly removed, collected in tubes, and immediately stored at $-20^{\circ} \mathrm{C}$ till been assayed for total testosterone, luteinizing hormone (LH), and follicle stimulating hormone (FSH) levels by using Enzyme
Linked Immuno-sorbent assay (ELISA) kits (Cayman Chemical Company, Ann Arbor, MI, USA). Hormones were assayed according to the methods described by the manufacturer's instructions enclosed with each kit. Serum concentrations of hormones were estimated colorimetrically at an absorbance spectrum wavelength of 450-nm using a spectrophotometric BioTek ELX-808 Ultramicroplate reader (BioTek Instruments Inc., Winooski, VT, USA).

Seminal quality analysis: The epididymis of each rat were dissected out and weighed then processed for evaluation of spermatozoa count or concentration, sperm motility, and sperm viability and morphology as previously described by Bearden and Fuquay (2000). Briefly, the epididymal sperm content of each rat was obtained after cutting the caudal part of the epididymis using surgical blades and squeezing it gently in a sterile clean glass tube, then it was diluted ten times with 2 . 9\% sodium citrate dihydrate aqueous solution and mixed thoroughly for light microscopic estimation of sperm characteristics at 400x magnification with reduced light as follows:

(A) Sperm count was carried out by loading $10 \mu \mathrm{l}$ of the aliquot on the side of the improved Neubauer's Haemocytometer counting chamber thereafter, the central grid was located and sperm cells were counted in five squares within the central grid.

(B) Sperm motility was determined by adding two drops of the suspension on worm slide and covering it with a coverslip then the incidence of progressively motile sperms was recorded.

(C) Sperm viability and morphologic abnormalities were detected by preparing thin semen smears stained with eosinnigrosin stain. Spermatozoal cells that appeared white in color and red or dark pink in color were recorded as live and dead sperms, respectively. One hundred 
sperm cells were examined per each rat in order to obtain the percentages of live and death spermatozoa.

On the other hand, testes were dissected and removed, washed with cold saline solution, freed of fat, and weighed. Each right and left testicle was cut transversely into 2 halves by sharp scalpel. One-half from each testis was processed for histopathological examination and the other half was prepared for ultrastructural study.

Histopathological preparations: The testicular specimens were fixed in Bouin's solution, subsequently dehydrated in ascending grades of alcohol, cleaned by xylene, and embedded in paraffin wax, then sectioned at $4 \mu \mathrm{m}$ thicknesses by a microtome. The slides were stained with Hematoxylin and Eosin ( $\mathrm{Hx}$ and $\mathrm{E})$ (Gamble and Wilson, 2002), Periodic Acid-Schiff Reaction (PAS) (Totty, 2002), and Masson's Trichrome (MT) (Jones, 2002). Mounted slides were examined and photographed using Leica DM500 binocular light microscope with an attached ICC50 HD color digital camera (Leica Microsystems Ltd, Heerbrugg, Switzerlan) at Department of Pathology, Benha Faculty of Medicine.

A total of 100 seminiferous tubules cross sections per each animal were randomly chosen from two non-serial tissue sections stained with $\mathrm{Hx}$ and $\mathrm{E}$ stain and examined microscopically by an expert pathologist in a blind fashion. Various histological parameters such as severity of testicular injury, histopathological alterations, and spermatogenesis maturity were determined, scored, and graded.

Histological examination of testicular lesions per each rat was performed using semi-quantitative scoring system as previously mentioned by Lanning et al. (2002). The severity of lesions was graded on a scale of $0-5$ based on the percentage of tubules affected as follows: 0 (normal for $<2 \%), 1$ (minimal for $<2 \%-<5 \%), 2$ (slight for 5\%-25\%), 3 (moderate for 25\%-50\%), 4 (marked for 50\%-75\%), and 5 (severe for $>75 \%$. In addition, for each animal, the percentages of normal and altered morphology of seminiferous tubules were determined and counted according to D'Cruz and Uckun (2000).

The number and percentage of Leydig cells/animal as well as normal and altered histology of Leydig cells in 100 triangular interstitial spaces per each rat were scored and graded as follows: 0 (total lack), 1 (15 cells), 2 (6-10 cells), 3 (11-30 cells), 4 (>30 cells) (Gumińska et al., 2007).

Quantitative assessment of testicular spermatogenesis was performed in at least 100 cross-sections of seminiferous tubules per each animal and the level of germinal epithelium maturation was given a score ranging from 1 to 10 according to the modified Johnsen testicular score method described by De Kretser and Holstein (1976). The following criteria were observed and graded: (1) no seminiferous epithelial cells, tubular sclerosis; (2) no germ cells, Sertoli cells only; (3) spermatogonia only; (4) no spermatids, few spermatocytes, arrest of spermatogenesis at the primary spermatocyte stage; (5) no spermatids, many spermatocytes; (6) no late spermatids, few early spermatids, arrest of spermatogenesis at the spermatid stage, disturbance of spermatid differentiation; (7) no late spermatids, many early spermatids; (8) few late spermatids; (9) many late spermatids, disorganized tubular epithelium; and (10) full spermatogenesis. Different lesions in the same section were graded separately and a mean score count was calculated by dividing the total score by the number of estimated tubules.

Ultrastructural preparations: Thin sections from testes were prepared according to the method of Millong (1961). Briefly, 1-3 mm segment of testis 
were fixed in fresh $3 \%$ glutaraldehydeformaldehyde at $4^{\circ} \mathrm{C}$ for $18-24 \mathrm{~h}$. The specimens were then washed in phosphate buffer (pH 7. 4) and post-fixed in isotonic $1 \%$ osmium tetroxide for $1 \mathrm{~h}$ at $4{ }^{\circ} \mathrm{C}$ and then processed. Semithin sections $(1 \mu \mathrm{m})$ were stained with toluidine blue and examined under the light microscope to confirm the presence of testicular tissue changes. Ultrathin sections $(70-80 \mathrm{~nm})$ were obtained from altered tissue sites using ultramicotome, mounted on copper grids, and stained with uranyl acetate and lead citrate. Finally, each grid was examined and photographed using JEOL JEM-100SX transmission electron microscope operating at an acceleration voltage of $80-\mathrm{kV}$ (Jeol Ltd, Tokyo, Japan), Electron Microscope Unit, Tanta University.

Statistical analysis: The collected data were tabulated and analyzed using Statistical Package for the Social Sciences version 16 software (SPSS, Chicago, IL). Quantitative data were expressed as mean and standard deviation (mean $\pm \mathrm{SD}$ ). Chi square test $\left(X^{2}\right)$ and one-way analysis of variance (ANOVA) were used as tests of significance. Significant ANOVA was followed by post-hoc Tukey HSD (Honest Significant Difference) test for multiple comparisons to detect significant pairs and values of $\mathrm{P}<0$. 05 were considered statistically significantly different.

\section{RESULTS}

No animal mortality was noticed in any of the three experimental groups throughout the study.

As shown in Table (1), the mean values of initial body weights of CQPgroup and HCS-group showed slight statistically insignificant decreases when compared with C-group value as well as each other.

On the other hand, there were statistically significant and insignificant reductions in the mean final body weight values of CQP-group and HCS-group, respectively, when compared with $\mathrm{C}$ group value and this difference was significantly lower in CQP-group than HCS-group.

In CQP-group, the mean values of absolute and relative weights of testes were statistically significantly decreased as compared with the corresponding values of $\mathrm{C}$-group and HCS-group. Similarly, the mean values of absolute and relative weights of epididymis in CQPgroup revealed statistically significant declines as compared with the corresponding values of C-group and HCS-group. However, in HCS-group, there were slight statistically insignificant decreases in absolute and relative weights of both testes and epididymis as compared with the corresponding values of C-group.

The mean values of sperm count, motility, live-dead sperm ratio, and normal sperm morphology in CQP-group were statistically significantly lower than the corresponding values of C-group and HCS-group, whereas the mean value of abnormal sperm morphology in CQPgroup depicted a statistically significant increase as compared to C-group and HCS-group. Although the mean values of the previous parameters were also decreased in HCS-group, except for the incidence of abnormal sperm morphology which increased, as compared with the corresponding values of C-group, the statistical differences were insignificant.

As appears in Table (2), CQP-group showed statistically significant depletions in serum levels of testosterone, $\mathrm{LH}$, and FSH when compared with the corresponding values of $\mathrm{C}$-group and HCS-group. On the other side, HCS-group showed statistically insignificant decrease in serum testosterone level as well as statistically significant reductions in serum levels of LH and FSH when compared with $\mathrm{C}$-group values.

As exhibit in Table (3),the incidence and severity of the degenerative changes 
in the SNT per animals were markedly increased in CQP-group (the severity of the lesions ranged from slight to severe) and slightly increased in HCS-group (the severity of the lesions ranged from minimal to slight) than C-group (the severity of the lesions was minimal), however, the prevalence of testicular lesions was substantially higher in CQPgroup than HCS-group and these differences were statistically significant among the three studied groups. Likewise, the number and percentage of animals associated with reduced Leydig cells were considerably greater in CQP-group and little higher in HCS-group than C-group, nonetheless, these changes were more predominant in CQP-group than HCSgroup and the differences between the three experimental groups were statistically significant.

As manifest in Table (4), the mean values of normal SNT score were statistically significantly and insignificantly decreased in CQP-group and HCS-group, respectively, as compared to C-group. Also, CQP-group depicted a statistically significant depression in the mean value of normal SNT score as compared to HCS-group. On the contrary, the mean values of abnormal SNT score were statistically significantly and insignificantly increased in CQP-group and HCS-group, respectively, as compared to C-group. Also, CQP-group depicted a statistically significant rise in the mean value of abnormal SNT score as compared to HCS-group.

The mean values of normal Leydig cells score elucidated statistically significant and insignificant decreases in CQP-group and HCS-group, respectively, as compared to C-group. Furthermore, the mean value of CQP-group showed a statistically significant decline as compared to HCS-group.

Contrariwise, the mean values of abnormal Leydig cells score displayed statistically significant and insignificant increments in CQP-group and HCS-group, respectively, as compared to $\mathrm{C}$-group. Moreover, the mean value of CQP-group demonstrated a statistically significant elevation as compared to HCS-group.

The mean values of spermatogenesis maturity score were statistically significantly and insignificantly reduced in CQP-group and HCS-group, respectively, as compared to C-group. Likewise, the mean value of CQP-group manifested a statistically significant diminish as compared to HCS-group.

\section{Light Microscopic Examination and Histopathological Results.}

Light microscopic examination of testicular tissue sections stained with H\&E from the C-group revealed normal appearance and arrangement of the structural components of the seminiferous tubules (SNT) and interstitial tissues in the intertubular spaces without any obvious histopathological lesions. The SNT are lined with stratified epithelium and consists of two types of cells, namely Sertoli and spermatogenic cells. Each SNT consists of regular well-delineated basement membrane (BM), well-preserved Sertoli cells (appears as triangular or oval cells resting on the $\mathrm{BM}$ ), and several layers of spermatogenic cells namely spermatogonia,

spermatocytes, spermatids, and mature spermatozoa. The interstitial spaces showed clusters of intact Leydig cells, which appeared polygonal in shape with rounded nuclei, as well as normal blood vessels that appeared patent without blood cells in the lumen (Figs. 12).

In CQP-group, light microscopic examination of the H\&E stained testicular sections revealed remarkable histopathological alterations such as atrophy, degeneration, and necrosis in considerable number of SNT as compared to C-group. The affected SNT exhibited irregular shape, disintegration of BM, 
separation between the basal layers of germ cells, vacuolation of the intercellular spaces, impairment of spermatogenesis and decrease in mature sperm numbers, and obliteration of the lumen or wide lumen with necrotic cell debris. The widened interstitial spaces between SNT showed dilated blood vessels, transudate, and inflammatory cellular infiltrates and the Leydig cells appeared distorted and scanty as compared to C-group (Figs. 3-6). On the contrary, histopathological examination of $H \& E$ stained testicular sections obtained from HCS treated animals showed mild degenerative changes in the germinal epithelium of some SNT present among several totally normal tubules and minor morphological changes in some Leydig cells as compared to C-group (Figs. 7-9). Consequently, administration of CQP caused more severe histological damages in rats' testes than HCS treatment.

On the other hand, light microscopic examination of testicular sections stained magenta with PAS from the C-group revealed normal distribution of PAS positive reaction where moderate staining affinity was noticed in the basement membranes of the SNT, heads of mature sperms, Leydig cells, and blood vessel walls (Fig. 10).

Testicular tissue examination of the CQP-group exhibited reduced staining affinity of PAS positive materials inside the SNT with disruption of SNT shape and separation and edema of the BM as well as edema of the interstitial space and dilated thick walled blood vessels as compared to C-group (Fig. 11). However, moderate staining affinity of PAS positive materials were recognized in HCS-group as compared to C-group (Fig. 12). Accordingly, administration of CQP was associated with marked diminution of testicular tissue polysaccharides contents as compared to HCS treatment.

Light microscopic examination of testicular sections stained with Masson's Trichrome from the C-group showed normal distribution pattern of the scanty collagen fibers tissue supporting the BM of the SNT, cellular membranes of the spermatogenic layers, and the interstitial tissues (Fig. 13). The testicular sections of CQP-group showed an increase in collagen fibers tissue formation of the $\mathrm{BM}$, interstitial tissues, and around the blood vessels with signs of fibrosis in the SNT as compared to C-group (Figs. 1415). However, in HCS-group, normal appearance of collagen fibers tissue distribution was noted in the SNT and their basement membranes and in the interstitial tissues without signs of fibrosis as compared to C-group (Fig. 16). According to that, CQP significantly increased the amount of collagen fibers formation and caused severe fibrotic lesions in the testes as compared to HCS.

\section{Electron Microscopic Examination} and Ultrastructural Results.

Examination of ultrathin testicular sections of the C-group showed normal morphological appearance of BM, spermatogonia, Sertoli cells, spermatocytes, spermatids, mature sperms, and Leydig cells (Figs. 17-20).

The BM or basal lamina that surrounded the seminiferous epithelium appeared regular and of uniform pattern with a single thin layer of flattened peritubular myoid cells.

The round spermatogonia, which rested against the BM of the SNT, evidenced rounded pale stained euochromatic nucleus and prominent nucleolus with peripheral heterochromatin clumps as well as many mitochondria and free ribosomes scattered within the cytoplasm.

Sertoli cells showed euchromatic infolded nuclei, prominent nucleoli, and a rim of peripheral dense chromatin. The cytoplasm of these cells extended from the basal lamina to the lumen of the SNT and 
envelops the adjacent germinal elements and contained abundant smooth endoplasmic reticulum, few strands of rough endoplasmic reticulum, welldeveloped Golgi complexes, mitochondria, lysosomes and electron dense bodies.

The primary spermatocytes appeared as large cells that connected together and with spermatids by inter-cellular bridges. They demonstrated the presence of large euochromatic spherical nuclei with areas of more condensed chromatin and scanty cytoplasm with peripherally arranged mitochondria, little endoplasmic reticulum, small clumps of ribosome, and few cluster of Golgi apparatus accumulated at one pole of the cell.

The spermatids appeared with large spherical euchromatic nuclei with chromatin clumps and many peripherally arranged mitochondria with clear matrix, well-developed Golgi apparatus, membrane bounded endoplasmic reticulum, and flattened acrosomal vesicles embedded in a lightly stained cytoplasm. The acrosomal granules appeared as an ovoid deep condensation enclosed in the acrosomal vesicle covering one third of the spermatid nucleus to form the acrosomes that subsequently spread over the anterior hemisphere of the spermatid nucleus to form the acrosomal cap (head cap). The head of sperm showed a pyramidal dark nucleus covered by acrosomal cap and transverse section in the middle piece showed centrally located microtubules which form the axoneme of the flagellum.

The interstitial Leydig cells evidenced regular outlines, large eccentric euchromatic indented nuclei, prominent nucleoli, and a rim of peripheral dense chromatin and cytoplasm filled with numerous mitochondria, smooth endoplasmic reticulum, Golgi complex, and moderate amount of lipid droplets.
Examination of ultrathin testicular sections of the CQP-group showed different degenerative changes in the Sertoli cells and germ cells gonadal parenchyma as well as in the interstitial Leydig cells (Figs. 21-26).

The degenerated peritubular BM of SNT appeared irregular or wavy, interrupted, thickened with scattered collagen fibers around it, and separated from germ cells. Alteration of Sertoli cells morphology such as fragmentation, necrosis, electrolucent areas or vacuolization within the cytoplasm, disturbed mitochondria, loss of contact between cells, detachment and wide intercellular spaces as well as focal disruption of the junctional complexes were detected. The damaged primary spermatocytes exhibited flattened or pyknotic nuclei with chromatin clumps and vacuolization of the cytoplasm. The devastated spermatids were complete or partial in many SNT and were accompanied with lack of mature sperm formation. Corrupted spermatids depicted poorly condensed nuclei, vacuoles within the acrosome material with very thin head cap covering the whole acrosome, degenerated mitochondria, cytoplasmic vacuolation, and marked sperms deformity. The degeneration Leydig cells appeared polymorphic in shape with irregular nuclei, greater amount of peripheral heterochromatin, dilated and vacuolated mitochondria, and increased lysosomal contents.

Examination of ultrathin testicular sections of the HCS-group showed nearly normal morphological appearance of BM, spermatogonia, Sertoli cells, spermatocytes, spermatids, mature sperms, and Leydig cells as compared to C-group (Figs. 27-29).

Consequently, ultrastructural adverse effects induced by $\mathrm{CQP}$ on testicular parenchyma were more extensive than those seen in HCS-group. 
Table (1): Analysis of variance statistical comparison of rats' body weights, absolute and relative weights of testes and epididymides, and seminal quality among the three groups.

\begin{tabular}{|c|c|c|c|c|}
\hline \multirow[b]{2}{*}{ Parameters } & \multicolumn{4}{|c|}{ Groups } \\
\hline & C-group & CQP-group & HCS-group & \begin{tabular}{|l} 
CQP vs \\
HCS \\
\end{tabular} \\
\hline \multicolumn{5}{|l|}{ Initial Body Weight (g) } \\
\hline Mean \pm SD & $196.1 \pm 9.62$ & $194.2 \pm 9.93$ & $195.4 \pm 9.5$ & \\
\hline P-value and Significance & & $0.900^{\mathrm{NS}}$ & $0.986^{\mathrm{NS}}$ & $0.959^{\mathrm{NS}}$ \\
\hline Change percentage & & $0.97(\downarrow)$ & $0.36(\downarrow)$ & $0.61(\downarrow)$ \\
\hline \multicolumn{5}{|l|}{ Finalbody weight (g) } \\
\hline Mean \pm SD & $232.4 \pm 14.42$ & $210.9 \pm 9.02$ & $226.7 \pm 15.1$ & \\
\hline P-value and Significance & & $0.003^{*}$ & $0.601^{\mathrm{NS}}$ & $0.031^{*}$ \\
\hline Change percentage & & $9.25(\downarrow)$ & $2.45(\downarrow)$ & $6.97(\downarrow)$ \\
\hline \multicolumn{5}{|c|}{ Absolutepaired-testes weight (g) } \\
\hline Mean \pm SD & $2.97 \pm 0.31$ & $2.22 \pm 0.46$ & $2.86 \pm 0.21$ & \\
\hline P-value and Significance & & $0.000^{*}$ & $0.753^{\mathrm{NS}}$ & $0.001^{*}$ \\
\hline Change percentage & & $25.25(\downarrow)$ & $3.7(\downarrow)$ & $22.38(\downarrow)$ \\
\hline \multicolumn{5}{|c|}{ Relativepaired-testes weight ${ }^{(ब)}$} \\
\hline Mean \pm SD & $1.28 \pm 0.14$ & $1.04 \pm 0.18$ & $1.27 \pm 0.02$ & \\
\hline P-value and Significance & & $0.001^{*}$ & $0.96^{\mathrm{NS}}$ & $0.002^{*}$ \\
\hline Change percentage & & $18.75(\downarrow)$ & $0.78(\downarrow)$ & $18.11(\downarrow)$ \\
\hline \multicolumn{5}{|c|}{$\begin{array}{l}\text { Absolutepaired-epididymal } \\
\text { weight (g) }\end{array}$} \\
\hline Mean \pm SD & $1.43 \pm 0.13$ & $1.13 \pm 0.14$ & $1.34 \pm 0.22$ & \\
\hline P-value and Significance & & $0.001^{*}$ & $0.475^{\mathrm{NS}}$ & $0.021^{*}$ \\
\hline Change percentage & & $20.98(\downarrow)$ & $6.29(\downarrow)$ & $15.67(\downarrow)$ \\
\hline \multicolumn{5}{|c|}{$\begin{array}{l}\text { Relativepaired-epididymal } \\
\text { weight }^{\Phi}\end{array}$} \\
\hline Mean \pm SD & $0.61 \pm 0.02$ & $0.53 \pm 0.05$ & $0.59 \pm 0.06$ & \\
\hline P-value and Significance & & $0.002^{*}$ & $0.462^{\mathrm{NS}}$ & $0.035^{*}$ \\
\hline Change percentage & & $13.11(\downarrow)$ & $3.28(\downarrow)$ & $10.17(\downarrow)$ \\
\hline \multicolumn{5}{|l|}{ Sperm count (million/ml) } \\
\hline Mean \pm SD & $59.48 \pm 4.38$ & $36.9 \pm 4.04$ & $56.68 \pm 4.57$ & \\
\hline P-value and Significance & & $0.000^{*}$ & $0.333^{\mathrm{NS}}$ & $0.000^{*}$ \\
\hline Change percentage & & $37.96(\downarrow)$ & $4.71(\downarrow)$ & $34.9(\downarrow)$ \\
\hline \multicolumn{5}{|l|}{ Motility (\%) } \\
\hline Mean \pm SD & $92.51 \pm 3.23$ & $38.74 \pm 5.23$ & $90.8 \pm 5.87$ & \\
\hline P-value and Significance & & $0.000^{*}$ & $0.719^{\mathrm{NS}}$ & $0.000^{*}$ \\
\hline Change percentage & & $58.12(\downarrow)$ & $1.85(\downarrow)$ & $57.33(\downarrow)$ \\
\hline \multicolumn{5}{|l|}{ Live-dead sperm ratio (\%) } \\
\hline Mean \pm SD & $91.2 \pm 3.05$ & $75.73 \pm 5.24$ & $89.3 \pm 6.04$ & \\
\hline P-value and Significance & & $0.000^{*}$ & $0.67^{\mathrm{NS}}$ & $0.000^{*}$ \\
\hline Change percentage & & $16.96(\downarrow)$ & $2.1(\downarrow)$ & $15.2(\downarrow)$ \\
\hline \multicolumn{5}{|l|}{ Normal sperm morpholog } \\
\hline Mean \pm SD & $86.77 \pm 4.2$ & $70.27 \pm 5.12$ & $84.57 \pm 4.7$ & \\
\hline
\end{tabular}




\begin{tabular}{|l|l|l|l|l|}
\hline P-value and Significance & & $0.000^{*}$ & $0.553^{\mathrm{NS}}$ & $0.000^{*}$ \\
\hline Change percentage & & $19.02(\downarrow)$ & $2.54(\downarrow)$ & $16.91(\downarrow)$ \\
\hline $\begin{array}{l}\text { Abnormal sperm morphology } \\
(\%)\end{array}$ & \multicolumn{4}{|l|}{} \\
\hline Mean \pm SD & $13.23 \pm 4.2$ & $29.73 \pm 5.12$ & $15.43 \pm 4.7$ & \\
\hline P-value and Significance & & $0.000^{*}$ & $0.553^{\mathrm{NS}}$ & $0.000^{*}$ \\
\hline Change percentage & & $124.72(\uparrow)$ & $16.63(\uparrow)$ & $92.68(\uparrow)$ \\
\hline
\end{tabular}

$\mathrm{CQP}=$ Chloroquine phosphate; $\mathrm{HCS}=\mathrm{Hydroxychloroquinesulphate;} \mathrm{C}$-group=Control-group; CQP-group=Chloroquine phosphate-group; $\mathrm{HCS}$-group=Hydroxychloroquine sulfate-group; g=Gram; vs=Versus; $@=$ =gram $/ 100$ gram body weight; \%=Percentage; *=Significant difference; NS=Non-significant difference; $\downarrow=$ Decrease; $\uparrow=$ Increase. Data shown as mean \pm standard deviation (SD); $P$-value of $>0.05$ is considered non-significant; $P$-value of $<0.05$ is considered significant.

Table (2): Analysis of variance statistical comparison of serum testosterone, LH, and FSH levels among the three groups.

\begin{tabular}{|c|c|c|c|c|}
\hline \multirow[b]{2}{*}{ Parameters } & \multicolumn{4}{|c|}{ Groups } \\
\hline & C-group & $\begin{array}{l}\text { CQP- } \\
\text { group }\end{array}$ & HCS-group & $\begin{array}{l}\text { CQP vs } \\
\text { HCS }\end{array}$ \\
\hline \multicolumn{5}{|l|}{ Testosterone (ng/dl) } \\
\hline Mean \pm SD & $3.56 \pm 0.28$ & $2.4 \pm 0.44$ & $3.36 \pm 0.26$ & \\
\hline P-value and Significance & & $0.000^{*}$ & $0.37^{\mathrm{NS}}$ & $0.000^{*}$ \\
\hline Change percentage & & $32.58(\downarrow)$ & $5.62(\downarrow)$ & $28.57(\downarrow)$ \\
\hline \multicolumn{5}{|l|}{ LH (mIU/ml) } \\
\hline Mean \pm SD & $2.84 \pm 0.31$ & $1.47 \pm 0.17$ & $2.39 \pm 0.18$ & \\
\hline P-value and Significance & & $0.000^{*}$ & $0.000^{*}$ & $0.000^{*}$ \\
\hline Change percentage & & $48.24(\downarrow)$ & $15.85(\downarrow)$ & $38.49(\downarrow)$ \\
\hline \multicolumn{5}{|l|}{ FSH (mIU/ml) } \\
\hline Mean \pm SD & 4. $24 \pm 0.24$ & $3.56 \pm 0.28$ & $3.91 \pm 0.31$ & \\
\hline P-value and Significance & & $0.000^{*}$ & $0.034^{*}$ & $0.024^{*}$ \\
\hline Change percentage & & $16.04(\downarrow)$ & $7.78(\downarrow)$ & $8.95(\downarrow)$ \\
\hline
\end{tabular}

$\mathrm{CQP}=\mathrm{Chloroquine}$ phosphate; $\mathrm{HCS}=\mathrm{Hydroxychloroquinesulphate;} \mathrm{C}$-group=Controlgroup; CQP-group=Chloroquine phosphate-group; HCS-group=Hydroxychloroquine sulfate-group; vs=Versus; LH=Luteinizing hormone; $\mathbf{F S H = F o l l i c l e ~ s t i m u l a t i n g ~}$ hormone; *=Significant difference; NS=Non-significant difference; $\downarrow=$ Decrease. Data shown as mean \pm standard deviation (SD); $P$-value of $>0.05$ is considered nonsignificant; $\boldsymbol{P}$-value of $<0.05$ is considered significant. 
Table (3): Chi-square statistical comparison of SNTdegeneration severity scoreand Leydig cells count score per each animal among the three groups.

\begin{tabular}{|l|l|l|l|}
\hline \multicolumn{2}{|c|}{ Parameters } & \multicolumn{3}{c|}{ Groups } \\
\cline { 2 - 4 } & C-group & CQP-group & HCS-group \\
\hline $\begin{array}{l}\text { SNT degeneration severity } \\
\text { score }\end{array}$ & & & \\
\hline Grade 0 (normal; <2\%) & $8 / 10(80 \%)$ & $0 / 10(0 \%)$ & $7 / 10(70 \%)$ \\
\hline Grade 1 (minimal; >2\%-<5\%) & $2 / 10(20 \%)$ & $0 / 10(0 \%)$ & $2 / 10(20 \%)$ \\
\hline Grade 2 (slight; 5\%-25\%) & $0 / 10(0 \%)$ & $1 / 10(10 \%)$ & $1 / 10(10 \%)$ \\
\hline Grade 3 (moderate; 25\%-50\%) & $0 / 10(0 \%)$ & $2 / 10(20 \%)$ & $0 / 10(0 \%)$ \\
\hline Grade 4 (marked; 50\%-75\%) & $0 / 10(0 \%)$ & $4 / 10(40 \%)$ & $0 / 10(0 \%)$ \\
\hline Grade 5 (severe; $>75 \%)$ & $0 / 10(0 \%)$ & $3 / 10(30 \%)$ & $0 / 10(0 \%)$ \\
\hline $\mathrm{X}^{2}$ test & & & \\
\hline $\mathrm{X}^{2}$ score & 28.6 & & \\
\hline Degrees of freedom & 10 & & \\
\hline$P$-value & $0.001 *$ & & \\
\hline Leydig cells score & & & \\
\hline Grade 0 (total lack) & $0 / 10(0 \%)$ & $0 / 10(0 \%)$ & $0 / 10(0 \%)$ \\
\hline Grade 1 (1-5 cells) & $0 / 10(0 \%)$ & $2 / 10(20 \%)$ & $0 / 10(0 \%)$ \\
\hline Grade 2 (6-10 cells) & $0 / 10(0 \%)$ & $3 / 10(30 \%)$ & $0 / 10(0 \%)$ \\
\hline Grade 3 (11-30 cells) & $1 / 10(10 \%)$ & $5 / 10(50 \%)$ & $2 / 10(20 \%)$ \\
\hline Grade 4 (>30 cells) & $9 / 10(90 \%)$ & $0 / 10(0 \%)$ & $8 / 10(80 \%)$ \\
\hline $\mathrm{X}^{2}$ test & & & \\
\hline $\mathrm{X}^{2}$ score & 21.8 & & \\
\hline Degrees of freedom & 8 & & \\
\hline$P$-value & $0.005^{*}$ & & \\
\hline
\end{tabular}

SNT=Seminiferous tubules; $\mathrm{C}$-group=Control-group; CQP-group=Chloroquine phosphate-group; HCS-group=Hydroxychloroquine sulfate-group; \#=Number and percentage of animals with specified lesions over the number of animals examined; $<=$ Less than; >=More than; $\%=$ Percentage; $\mathrm{X}^{2}=$ Chi-square; $*=$ Significant difference;

$P=$ Probability. 
Table (4): Analysis of variance statistical comparison of SNT and Leydig cells semiquantitative histopathological scores and spermatogenesis maturity score among the three groups.

\begin{tabular}{|l|l|l|l|l|}
\hline \multicolumn{1}{|c|}{ Parameters } & \multicolumn{4}{c|}{ Groups } \\
\cline { 2 - 5 } & C-group & \multicolumn{1}{c|}{ CQP-group } & HCS-group & $\begin{array}{l}\text { CQP vs } \\
\text { HCS }\end{array}$ \\
\hline Normal SNT morphology & & & & \\
\hline Mean \pm SD & $94.3 \pm 2.16$ & $50.5 \pm 21.26$ & $91.7 \pm 8.68$ & \\
\hline P-value and Significance & & $0.000^{*}$ & $0.901^{\mathrm{NS}}$ & $0.000^{*}$ \\
\hline Change percentage & & $46.45(\downarrow)$ & $2.76(\downarrow)$ & $44.93(\downarrow)$ \\
\hline Abnormal SNT morphology & & & & \\
\hline Mean \pm SD & $5.7 \pm 2.16$ & $49.5 \pm 21.26$ & $8.3 \pm 8.68$ & \\
\hline P-value and Significance & & $0.000^{*}$ & $0.901^{\mathrm{NS}}$ & $0.000^{*}$ \\
\hline Change percentage & & $768.42(\uparrow)$ & $45.61(\uparrow)$ & $496.39(\uparrow)$ \\
\hline Normal Leydig cells & & & & \\
\hline Mean \pm SD & $35.5 \pm 5.19$ & $6.5 \pm 3.95$ & $27.3 \pm 13.32$ & \\
\hline P-value and Significance & & $0.000^{*}$ & $0.1^{\mathrm{NS}}$ & $0.000^{*}$ \\
\hline Change percentage & & $81.69(\downarrow)$ & $23.1(\downarrow)$ & $76.19(\downarrow)$ \\
\hline Abnormal Leydig cells & & & & \\
\hline Mean \pm SD & $3.2 \pm 1.32$ & $7.1 \pm 4.58$ & $3.8 \pm 1.69$ & \\
\hline P-value and Significance & & $0.016^{*}$ & $0.891^{\mathrm{NS}}$ & $0.045^{*}$ \\
\hline Change percentage & & $121.88(\uparrow)$ & $18.75(\uparrow)$ & $86.84(\uparrow)$ \\
\hline $\begin{array}{l}\text { Spermatogenesis } \\
\text { score }\end{array}$ & & & & \\
\hline Mean \pm SD & & & & \\
\hline P-value and Significance & $9.36 \pm 0.34$ & $6.44 \pm 0.45$ & $9.1 \pm 0.38$ & \\
\hline Change percentage & & $0.000^{*}$ & $0.316^{\mathrm{NS}}$ & $0.000^{*}$ \\
\hline & & $31.2(\downarrow)$ & $2.8(\downarrow)$ & $29.23(\downarrow)$ \\
\hline
\end{tabular}

SNT=Seminiferous tubules; $\mathrm{CQP}=\mathrm{Chloroquine}$ phosphate;

HCS=Hydroxychloroquinesulphate; vs=Versus; \#=Spermatogenesis maturity of the germinal epithelium according to modified Johnsen's score; *=Significant difference; NS=Nonsignificant difference; $\downarrow=$ Decrease; $\uparrow=$ Increase. Data shown as mean \pm standard deviation (SD); $\boldsymbol{P}$-value of $>0.05$ is considered non-significant; $\boldsymbol{P}$-value of $<0.05$ is considered significant. 


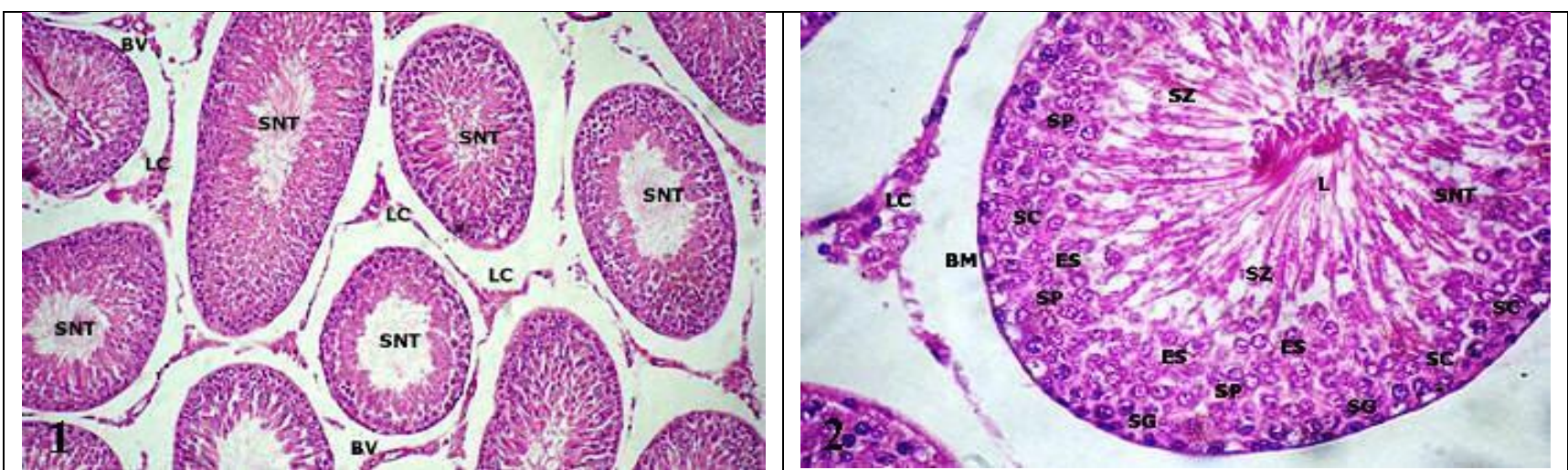

Figs. (1 and 2): Photomicrographs of H\&E-stained cross-sections of rats' testes prepared from C-group. Fig. (1): Showing normal tissue architectures with well-arranged seminiferous tubules (SNT) and normal interstitial cluster of Leydig cells (LC) and blood vessel (BV) (Original Magnification [OM] x 100). Fig. (2): Showing parts of seminiferous tubules (SNT) with normal appearance and arrangement of different germ cells including spermatogonia (SG), Sertoli cells (SC), spermatocytes (SP), early spermatids (ES), and mature spermatozoa (SZ) inside the lumen (L) surrounded by smooth regular basement membrane (BM) together with normal interstitial cluster of Leydig cells (LC). (OM x 400).

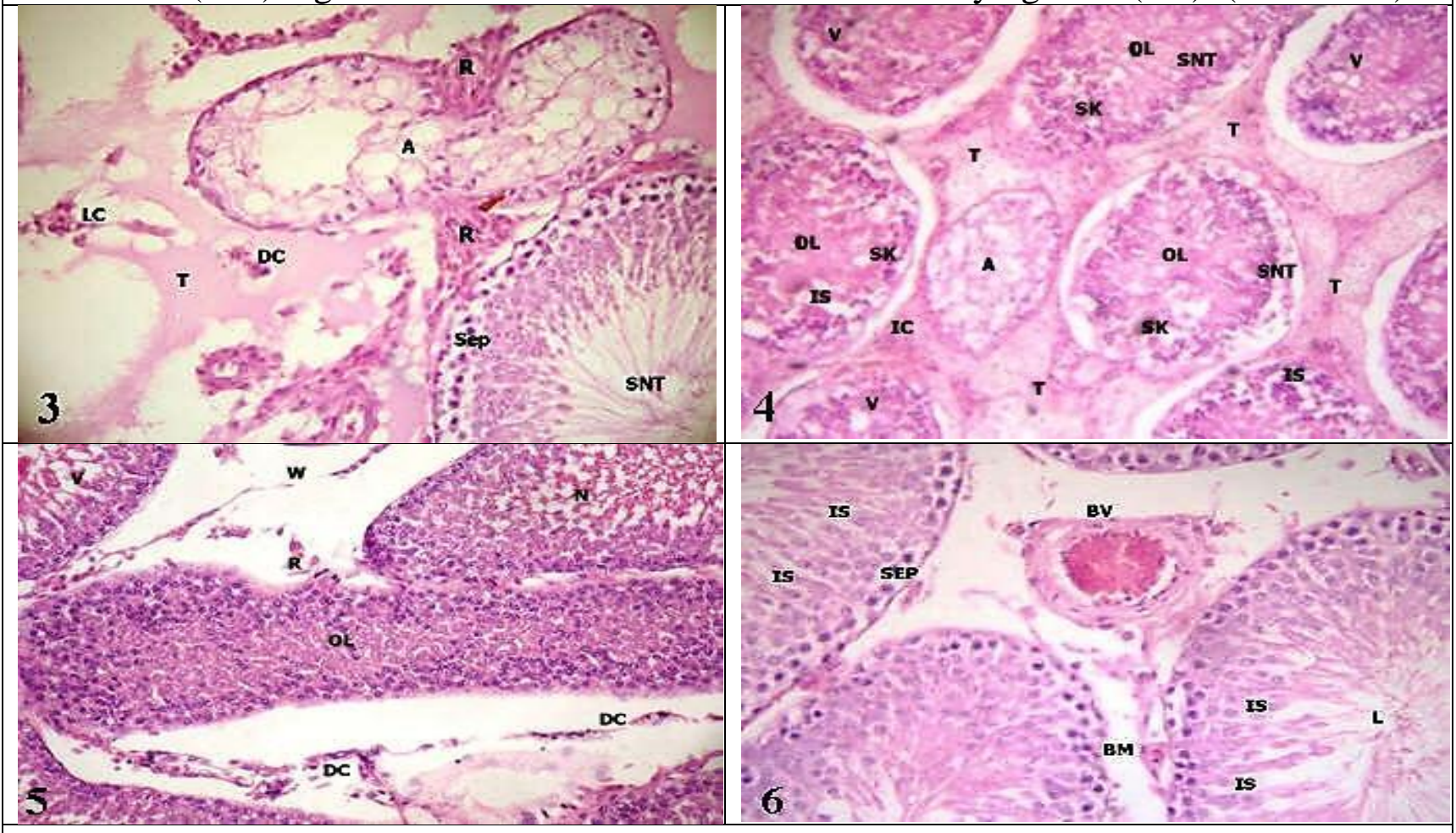

Figs. (3-6): Photomicrographs of H\&E-stained cross-sections of rats' testes prepared from CQP-group showing several severe degenerative changes in testicular parenchyma in the form of deformed seminiferous tubules (SNT), corrugated basement membrane (BM), disintegration or rupture of the BM (R), disorganization and separation between the basal layers of germ cells (Sep), atrophic tubule (A), shrinkage (SK) and vacuolation of SNT (V), widening of the intercellular spaces (IS), inflammatory cells infiltration (IC), obliterated lumen (OL), necrosis of SNT cells $(\mathrm{N})$, impairment of spermatogenesis and reduction in mature sperm numbers inside the lumen (L), widening of the intertubular space with lacking of interstitial cells between SNT (W), extensive transudate (T), desquamated cells (DC), thick-walled dilated and congested blood vessel (BV), and altered or absent Leydig cells (LC). (Figs. 3, 5, and 6: OM x 400; Fig. 4: OM x 200). 


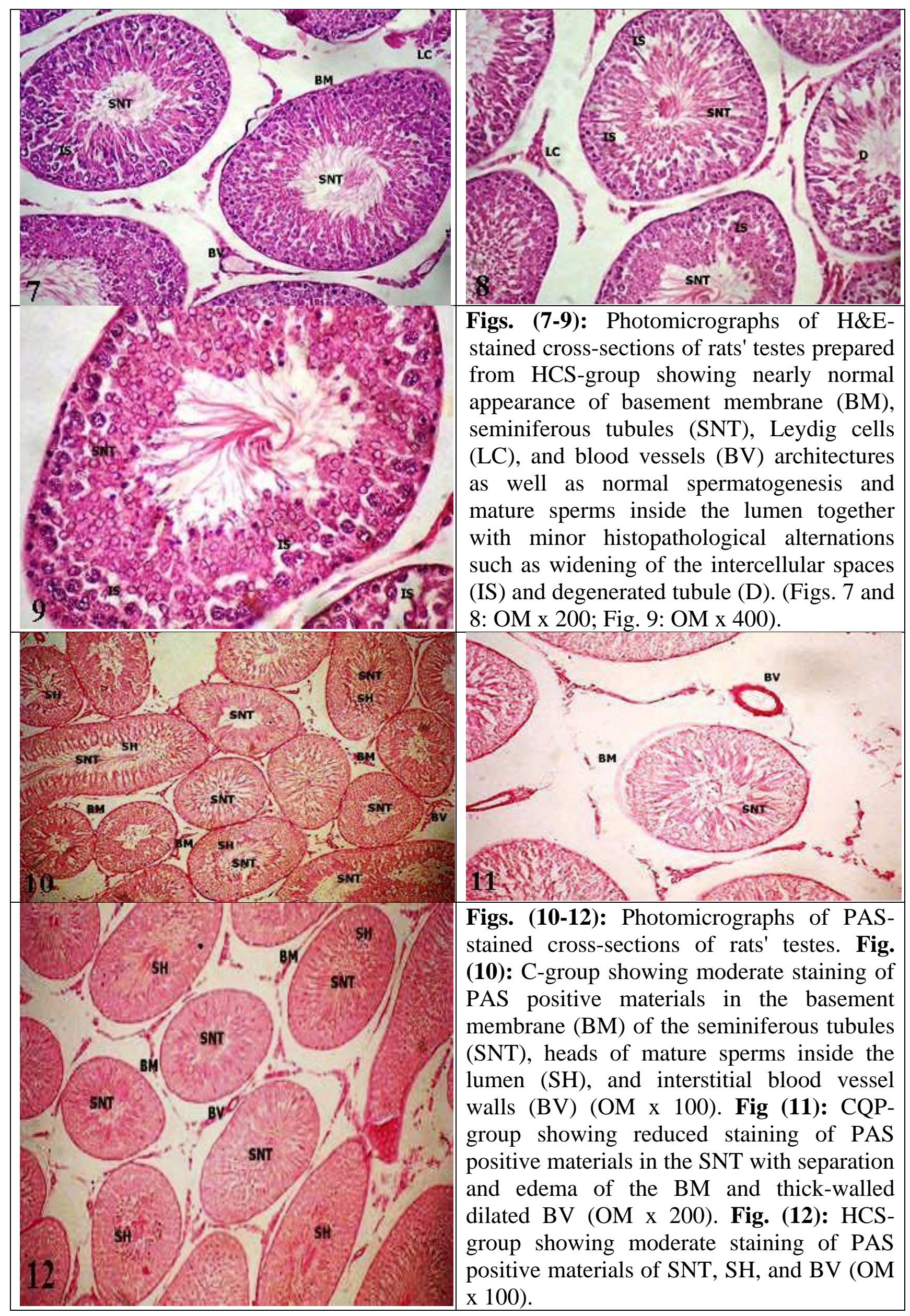




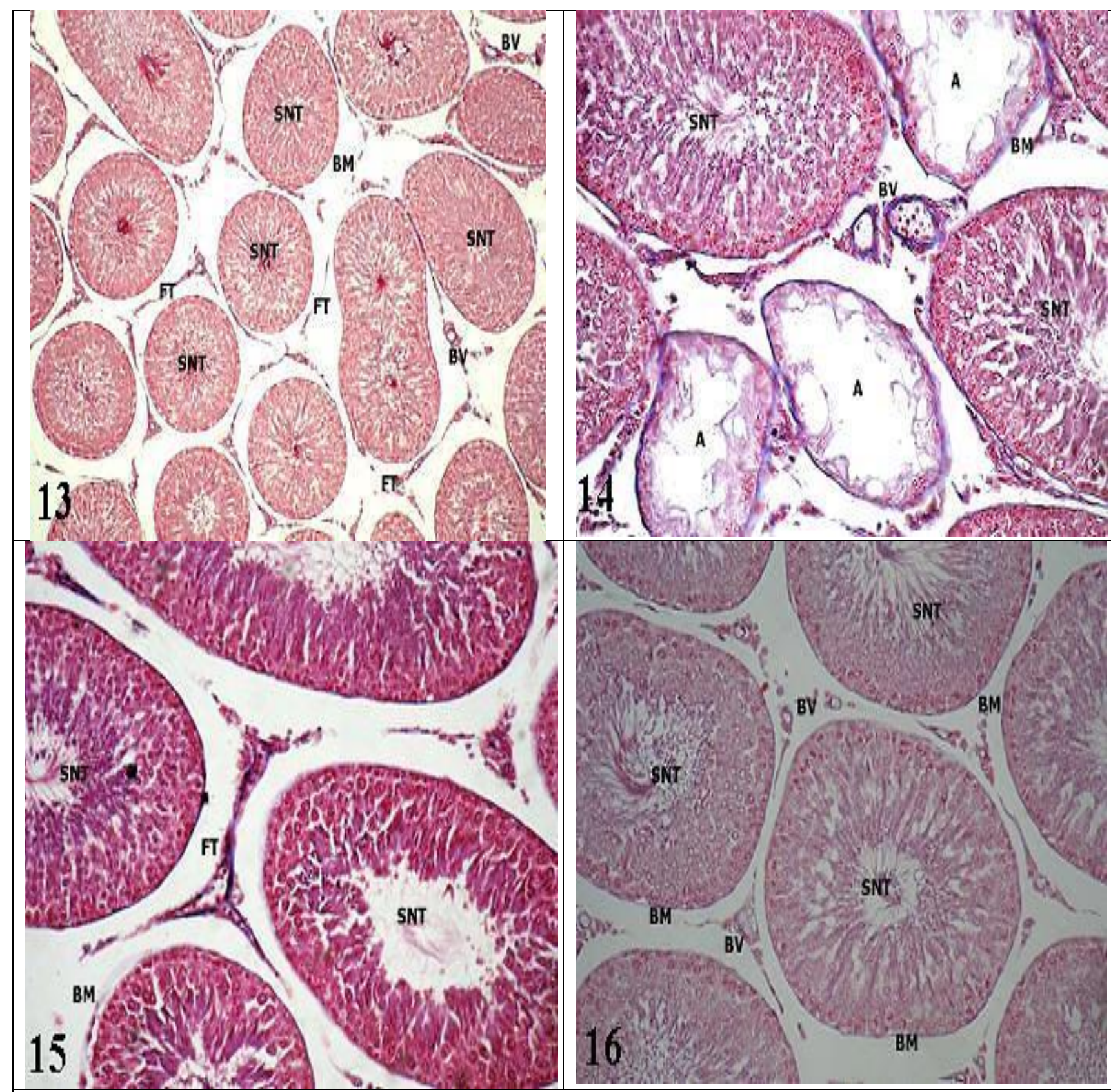

Fig. (13-16): Photomicrographs of Masson's Trichrome-stained cross-sections of rats' testes.

Fig. (13): A cross-section prepared from C-group showing normal distribution of the scanty collagen fibers tissue (FT) supporting the basement membrane (BM) of the seminiferous tubules (SNT) and spermatogenic cell layers, the interstitial tissue, and blood vessel walls (BV) (OM x 100). Figs. (14 and 15): Cross-sections prepared from CQP-group showing an increase in collagen FT formation of the BM, BV, and interstitial tissues as well as atrophic tubules (A) and separation and edema of the BM (Fig. 14: OM x 200; Fig. 15: OM x 400). Fig. (16): A cross-section prepared from HCS-group showing normal distribution of the scanty collagen FT supporting the BM of the SNT and spermatogenic cell layers, the interstitial tissue, and BV (OM x 200). 


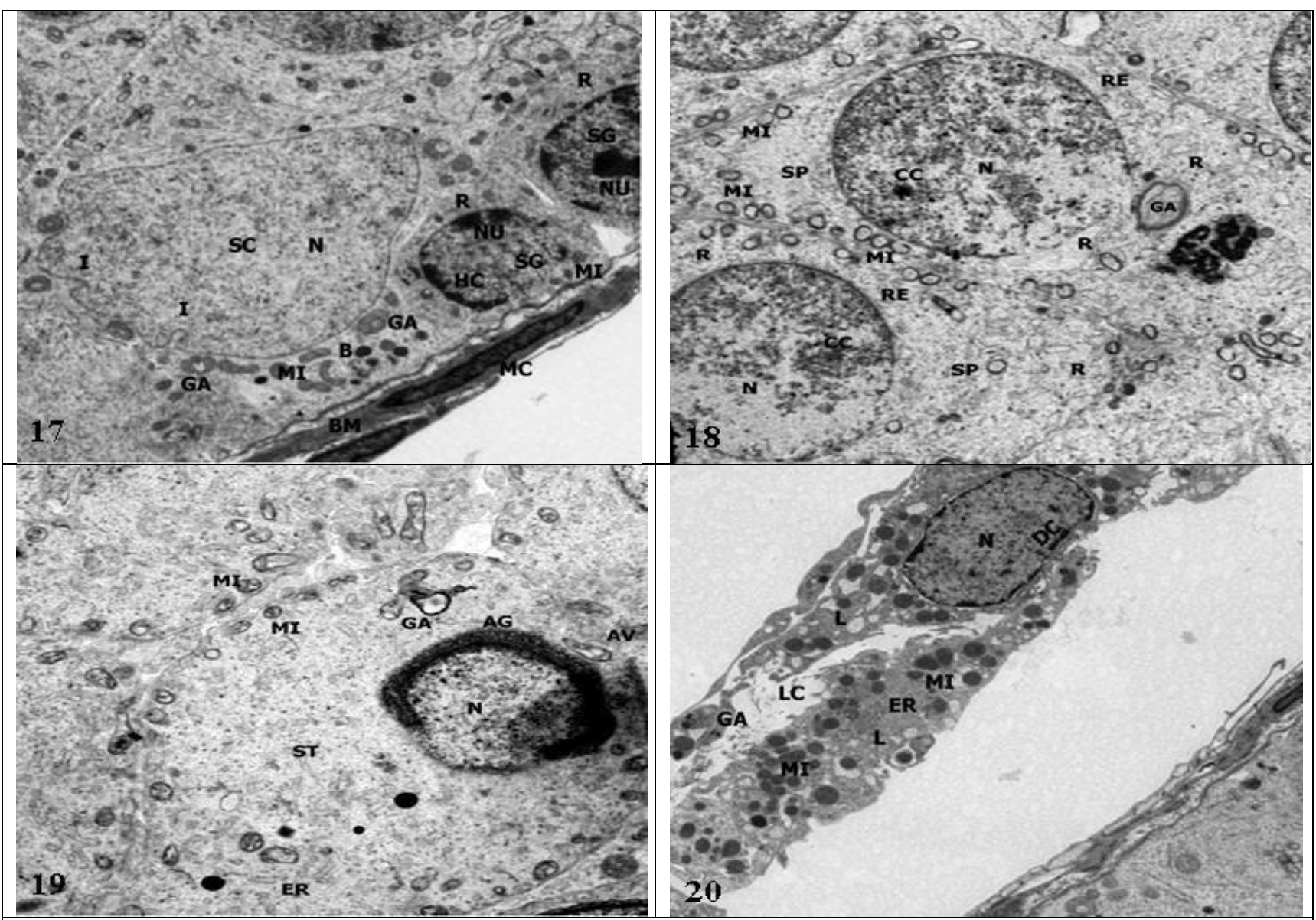

Figs. (17-20): Electron micrographs of ultrathin sections of adult rats' testes prepared from C-group. Fig. (17): Showing normal appearance of basement membrane (BM) with its flattened peritubular myoid cells (MC), spermatogonia (SG) with its rounded euochromatic nucleus, prominent nucleolus (NU), and peripheral heterochromatin clumps (HC), as well as many mitochondria (MI) and scattered ribosomes (R) within the cytoplasm, and Sertoli cells (SC) with its infolded (I) euchromatic nucleus (N), and abundant MI, well-developed Golgi apparatus (GA), and electron dense bodies (B) within the cytoplasm (OM X 1500). Fig. (18): Showing normal appearance of primary spermatocyte cells (SP) with its euochromatic spherical $\mathrm{N}$ and areas of condensed chromatin (CC) as well as scanty cytoplasm with peripherally arranged MI, endoplasmic reticulum (ER), R, and GA (OM X 2000). Fig. (19): Showing normal appearance of spermatid cell (ST) with its peripherally arranged MI and clear matrix, well-developed GA, ER, cytoplasmic acrosomal vesicles (AV), and ovoid deep condensation acrosomal granules (AG) covering the spermatid nucleus $(\mathrm{N})(\mathrm{OM} X$ 2500). Fig. (20): Showing normal appearance of the interstitial Leydig cell (LC) with its eccentric euchromatic $\mathrm{N}$ and a rim of peripheral dense chromatin (DC) as well as MI, ER, GA, and lipid droplets (L) filling the cytoplasm (OM X 1500). 


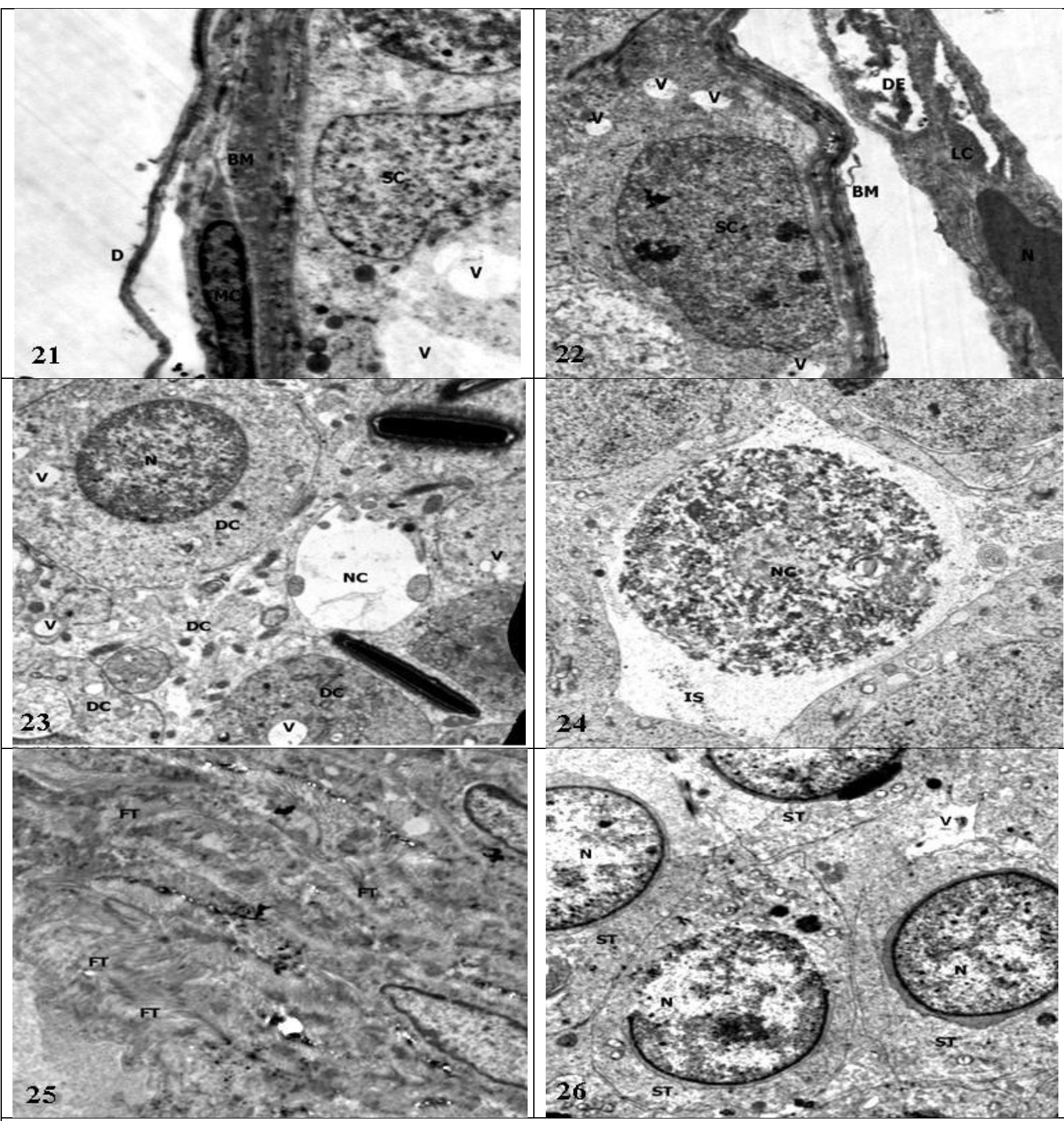

Figs. (21-26): Electron micrographs of ultrathin sections of adult rats' testes prepared from CQP-group showing various ultrastructureal changes in testicular tissues in the form of detachement, corrugation, and wall thickening of the basement membrane (BM) with degenerated myoid cells (MC), degenerative changes in Sertoli cells (SC) with irregular heterochromatine nucleus, degenerated (DE) Leydig cell (LC) with pyknotic nucleus $(\mathrm{N})$, multiple degenerated germ cells (DC) with vacuolated cytoplasm (V), necrotic germ cells (NC) with wide intercellular space (IS), interstitial tissue fibrosis (FT), and multiple degenerated spermatid cells (ST) with irregular heterochromatine nuclei $(\mathrm{N})$ (Figs. 21, 22, 24, 25, and 26: OM x 2000; Fig. 23: OM x 2500). 

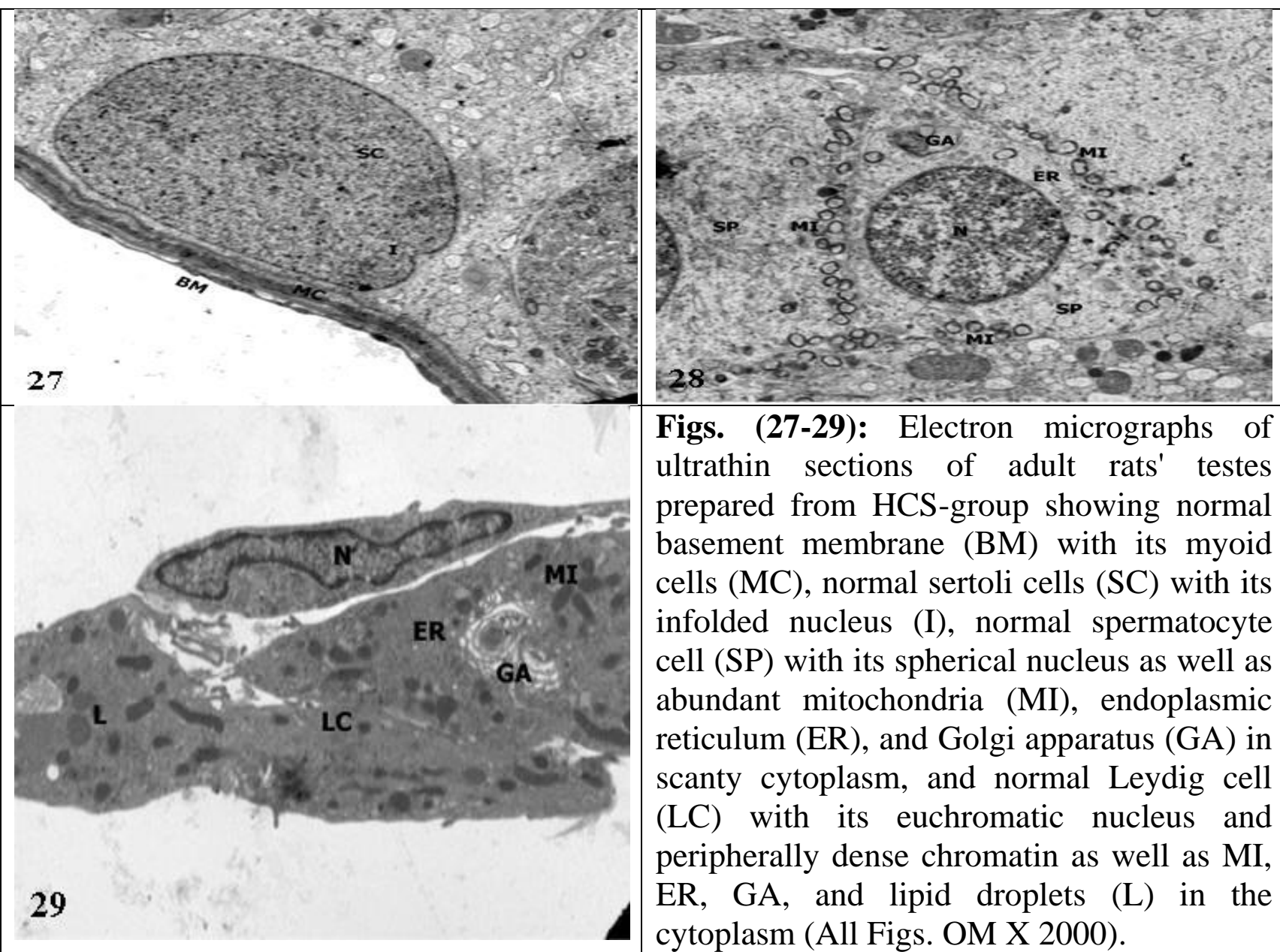

Figs. (27-29): Electron micrographs of ultrathin sections of adult rats' testes prepared from HCS-group showing normal basement membrane (BM) with its myoid cells (MC), normal sertoli cells (SC) with its infolded nucleus (I), normal spermatocyte cell (SP) with its spherical nucleus as well as abundant mitochondria (MI), endoplasmic reticulum (ER), and Golgi apparatus (GA) in scanty cytoplasm, and normal Leydig cell (LC) with its euchromatic nucleus and peripherally dense chromatin as well as MI, ER, GA, and lipid droplets (L) in the cytoplasm (All Figs. OM X 2000).

\section{DISCUSSION}

Chloroquine phosphate (CQP) and hydroxychloroquine sulfate (HCS) are commonly and extensively prescribed by physicians for the treatment of malaria and autoimmune diseases such as rheumatoid arthritis and systemic lupus erythematosus (Taherian et al., 2013). Despite this, their effects on male reproductive functions are not well known (Østensen et al., 2006). Hence, the present study was carried out to investigate the toxic effects of these two drugs on the reproductive functions of adult male albino rats.

The present results of CQP-group showed significant reductions in the final weight gains of body, testes, and epididymis, which are in agreement with the results of other researchers who hypothesize that long-term and/or shortterm administrations of CQP to experimental animals are associated with significant decreases in the weights of body (Mbajiorgu et al., 2008; Clewell et al., 2009), testes (Nicola et al., 1997; Okanlawon and Ashiru, 1998; Ekaluo et al., 2008; Desai et al., 2012), and accessory sex organ, including epididymis (Nicola et al., 1997; Ekaluo et al., 2008).

On the contrary, other researches show different results such as significant increase or insignificant changes in body weights as well as no changes in testicular weights after chronic administration of CQP to experimental animals (Nduka and Dada, 1987; Adjene and Adenowo, 2005).

These losses in weight gains may be due to protein deficiency secondary to suppression of appetite and low caloric intake (Mbajiorgu et al., 2008). The changes in weights of male sexual organs after administering CQP may be mediated via its direct toxic effects (Osinubi et al., 2006; Niu et al., 2016), androgen deprived action (Okanlawon et al., 1990; 
Nicola et al., 1997; Oforah et al., 2004), and regressive alternations in SNT with significant reduction in germinal epithelial and tubules volumes, the number of spermatogenic elements, and spermatozoa (Okanlawon and Ashiru, 1998; Asuquo et al., 2007).

The instant results of HCS-group demonstrated insignificant changes in the final weight gains of body, testes, and epididymis, which are similar to the findings of other authors who observe that oral administration of HCS may significantly prevent loss of body weight in diabetic rats (Pareek et al., 2009) and administrations of structurally related antimalarial drugs such as artesunate and artemisininare accompanied with insignificant effects on the testicular and epididymal weights (Izunya et al., 2010; Olumide and Raji, 2011; Farombi et al., 2014). Pareek et al. (2009) suggest that administration of HCS to adult male rats has no effects on water and food intake.

Administrations of antimalarial drugs to different laboratory animals are coupled with male reproductive dysfunction and infertility due to impairment of spermatogenesis (Osinubi et al., 2006; Olumide and Raji, 2011).

The present results of CQP-induced significant abnormalities in epididymal sperm quality are consistent with several other studies which reveal significant depression of sperm count (Nicola et al., 1997; Okanlawon and Ashiru, 1998) and impairment of sperm motility (Okanlawon et al., 1993; Adeeko and Dada, 1998; Salman and Ajayi, 2007) along with significant increase in the frequency of abnormal sperm morphology (Nicola et al., 1997) in animalsafter CQP treatment. Furthermore, in vitro incubation of CQP with human spermatozoa at higher concentrations results in significant inhibition of rapid sperm motility with subsequent increase in the percentage of static sperm (Trifunac and Berstein, 1982; Hargreaves et al., 1998).

The changes in seminal quality following CQP administration may be due to its significant excretion in semen by passive diffusion (Adeeko and Dada, 1994) with subsequent direct spermatoxic effect, inhibition of the sperm oxidative metabolism and glycolysis (Trifunac and Berstein, 1982), suppression of cholinesterase activity (Katewa and Katyare, 2005), marked decrease in serum levels of glucose, calcium, and protein, and/or increase in glucagon level (Gaafar et al., 2002). Also, CQP is a lysosome stabilizer that acts as a protease inhibitor and thus may inhibit the acrosome reaction of spermatozoa and reduce their fertilization capacity (Grunewald et al., 2007). Additionally, incubation of human spermatozoa with CQP significantly decrease sperm motility, viability, adenosine triphosphate level, and intracellular calcium concentration via acting as an autophagy inhibitor (Aparicio et al., 2016).

Contrary to this, many authors report that CQP markedly stimulates the motility of porcine and bovine spermatozoa in vitro and improves the fertilizing capacity of caudal spermatozoa. The authors speculate that this enhancement of sperm activity by CQP may be mediated via stimulation of the adenylcyclase system with subsequent increase in spermatozoal adenosine monophosphate activity and increase of the rate of loss of acetylcholinesterase activity during sperm transit within the cauda epididymis (Norman and Gombe, 1975; Egbunike, 1982).

The present findings of HCS-induced insignificant abnormalities in epididymal sperm quality are also in line with many authors who mention that administration of HCS does not cause impairment in 
male fertility (Ostensen, 2006; Silva et al., 2010).

There are conflicting reports about the effects of antimalarial preparations on testosterone, LH, and FSH levels. Several antimalarial drugs may significantly lower serum and/or testicular testosterone levels both in vivo and in vitro experimental models (Osinubi et al., 2006; Obianime and Aprioku, 2009), whereas other studies document insignificant effects of various antimalarial preparations on male rats reproductive hormones (Olumide and Raji, 2011; Farombi et al., 2012; Farombi et al., 2014; Niu et al., 2016) and in adult men (Ejebe et al., 2008).

The current result of CQP-induced significant change in the serum level of testosterone is compatible with many other studies which manifest suppressions of circulating (Okanlawon et al., 1990; Nicola et al., 1997; Ebonget al., 1999; Oforah et al., 2004) and testicular (Clewell et al., 2009) levels of testosterone in experimental animals after administration of CQP. Also, acute injection of CQP to pubertal rats inhibits testicular testosterone secretion in vitro and interferes with human chorionic gonadotropin stimulation test (Nduka and Dada, 1984).

Unlike to this, several other studies demonstrate insignificant influences of CQP on serum testosterone concentration in vivo (Salman et al., 2010) as well asin vitro testicular testosterone secretion in adult, prepubertal, and postpubertal rats (Nduka and Dada, 1984 and 1987). Additionally, administration of therapeutic doses of CQP to healthy adult male volunteers for 3 days does not cause any alternations in the levels of plasma testosterone (Ejebe et al., 2008).

The current result of HCS-induced insignificant change in the serum level of testosterone is concordant with other researches which exhibit no changes in serum testosterone levels in dogs and monkeys after receiving different oral doses of mefloquine for 90 consecutive days (a 4-aminoquinoline derivative closely related to HCS) (Korte et al., 1979). Also, the clinical study of Mok and Lau (2000) illustrate insignificant difference of testosterone levels between male patients receiving immunosuppressive drugs, including HCS, and normal control individuals. In addition, abnormal reproductive hormones in female patients are markedly improved after 6-month of treatment with HCS alone as evidenced by significant increase in their serum testosterone levels when post-treatment and pre-treatment values compared together (Wu et al., 2015). Dissimilar to this, some male patients under immunosuppressive therapy, including HCS, have shown low testosterone levels as compared to normal control values (Mok and Lau, 2000).

The effects of antimalarial preparations on gonadotrophins levels are heterogeneous. Many studies show significant reduction in serum levels of LH and FSH (Obianime and Aprioku, 2009; El-Sharaky et al., 2010), whereas other articles depict non-significant changes in serum gonadotrophins levels (Ejebe et al., 2008; Olumide and Raji, 2011; Farombi et al., 2014) after administrations of various antimalarial preparations to experimental animals.

The current findings of CQP-induced significant changes in the serum level of LH and FSH are concordant with many other articles which showing significant reductions in the blood levels of both $\mathrm{LH}$ in experimental rats (Oforah et al., 2004) and $\mathrm{FSH}$ in healthy adult male volunteers (Ejebe et al., 2008) after CQP treatment.

On the contrary, administration of CQP causes significant increase in LH levels along with insignificant alternation in FSH levels in mature male rats 
(Okanlawon et al., 1990) and significant elevation in the blood levels of LH in healthy adult male volunteers (Ejebe et al., 2008).

The current findings of HCS-induced significant alternations in the serum level of LH and FSH are congruent with other publication which exhibiting marked improvement of abnormal reproductive hormones in female patients after 6-month therapy with HCS as notice by significant decreases in their serum LH and FSH levels (Wu et al., 2015). Opposite to this, the overall concentrations of gonadotrophins remain significantly higher among male patients with HCS therapy as compared to the corresponding values of control individuals (Mok and Lau, 2000).

The toxic effects of CQP on male reproductive hormones may be mediated via reduction in testicular cholesterol synthesis (Clewell et al., 2009)as well as inhibitions of androgen stimulatory effects of human chorionic gonadotropin (Nduka and Dada, 1984), prostaglandin (Sairam, 1978), phospholipase $A_{2}$ (Didolkar and Sundaram, 1989), leading to suppression of steroid synthesis in testis. Thus, CQP can produce inhibition of phospholipid metabolism and reduction in intracellular arachidonic acid signaling, a necessary component of steroidogenic pathway, and may cause down-regulation of several genes responsible for cholesterol transport and steroid synthesis, resulting in suppression of hormonal productions (Clewell et al., 2009). In addition, it may increase cellular aggregation of epidermal growth factor by inhibiting its lysosomal degradation which prevents testicular steroidogenesis (Hsuah et al., 1981). Also, excessive formation of fibrous tissue may irreversibly alter testicular spermatogenesis and steroidogenesis secondary to Leydig and Sertoli cells dysfunctions (Oforah et al., 2004).
Chronic treatment of rats with CQP may diminish testicular protein synthesis and decrease enzymes activities of microsomal cytochrome $\mathrm{p} 450$, cytochrome $\mathrm{b} 5$, and nicotinamide adenine dinucleotide phosphate cytochrome c reductase either by indirect DNA intercalation of the gene that is necessary for various protein expressions or by disruption of the structures of interstitial, peritubular, Leydig, and Sertoli cells, resulting in reduction of testosterone, $\mathrm{LH}$, and $\mathrm{FSH}$ blood levels (Oforah et al., 2004).

Antimalarial compounds have been shown to induce deleterious effects on the structures of the testis especially the seminiferous tubules (SNT) of the treated animals. The severity of testicular lesions is time and dose dependent (Osinubi et al., 2006; El-Sharaky et al., 2010; Olumide and Raji, 2011; Farombi et al., 2012; Farombi et al., 2014; Niu et al., 2016).

The existing work revealed different structural and ultrastructural lesions in rats' testicular parenchyma as well as in the interstitial tissues that were markedly severe in CQP-group. Comparably, histopathological changes in testicular tissue architectures have been reported in several other experimental studies after treatment with CQP. Long-term administration of CQP to experimental animals causes multiple testicular degenerative changes such as edema of interstitial or Leydig cells and basal membrane, necrosis of SNT and Sertoli cells, disappearance of the tubular lumen, fibrosis, and capillary vessels dilatation (Oforah et al., 2004), numerical reduction of the Leydig cells, irregular and isolated SNT with concomitant detachment of spermatocytes, and disruption of intertubular stroma (Ebong et al., 1999; Asuquo et al., 2007), significant reduction in the size of SNT (Okanlawon and Ashiru, 1998), and lacking of germinal 
cell layer and sperm, pyknotic nuclei of germinal cells, vacuolization of the interstitium, and vacuolated cytoplasm of Leydig cells (Desai et al., 2012).

On the contrary, the study ofAbolghasemi et al. (2012) does not show any adverse effects of CQP on the mice testes infected with Plasmodium berghei after four consecutive days of its administration.

In the existing work, structural and ultrastructural examinations of testicular tissue sections of HCS-group showed nearly normal morphological appearance of the architectures with only minor morphological changes in some SNT. Analogous to this, there is no histopathological evidence of alternations in the testes, prostate, or epididymis after oral administration of mefloquine for 3month to dogs and monkeys (an antimalarial drug closely related to HCS) (Korte et al., 1979).

The pathogenic mechanism (s) of CQP-induced testicular toxicity and impairment of male reproductive functions may be explained by multi-factorial processes. Administration of CQP may disrupt the structural integrity of the testes and other organs via acting directly or indirectly on antioxidant status, leading to disturbance of oxidants/antioxidants balance with subsequent generation of multiple free radicals and development of oxidative stress as evidenced by significant decline in superoxide dismutase (a detoxifying enzyme catalyzes the dismutation of superoxide radical to hydrogen peroxide and oxygen) and remarkable depletion of hydrogen peroxide-decomposing enzymes such as catalase and glutathione peroxidase as well as increase in thiobarbituric acidreactive substances (byproduct of lipid peroxidation) due to accumulation of superoxide radical. Additionally, CQP may disrupt the functions of some testicular regulatory enzymes such as elevation of the acid phosphatase activity as well as depression of alkaline phosphatase, succinate dehydrogenase, and adenosine triphosphatase activities (Magwere et al., 1997; Desai et al., 2012).

Also, CQP, as an autophagy inhibitor or knockdown of a specific key protein component of the autophagy pathway by small or short interfering ribonucleic acid, may induce interstitial fibrosis by several different mechanisms including aggravation of up-regulation and accumulation of cellular type I collagen and fibronectin tissues (Liu et al., 2016), inhibition of lysosomal enzyme activity participate in the internalization of proteins and receptors, leading to prohibition of insulin-like growth factorbinding proteins-3 reduction and increase proteoglycan content (Smith et al., 1994), and suppression of intracellular degradation of procollagen protein thus increasing the accumulation and production of collagen (Eleftheriades et al., 1995). Oforah et al. (2004) state that abnormal deposition of collagen and proteoglycan production resulting in generation of fibrosis within extracellular matrix of testicular tissues and adversely affect cell activities and integrity with disappearance of the lumen.

The minor toxic effects of HCS on male gonadal system may be explained by the fact that it is 2-3 times less toxic than CQP in animal studies (McChesney, 1983) and it does not inhibit cyclooxygenases or decrease prostaglandin production (Ben-Chetrit et al., 2005).

Finally, the present work may disagree with other several studies. This variability might be explained on the basis of difference in dosage regimen (therapeutic or toxic; single or repeated), route of administration (oral or injection), 
duration of drug administration (short- or long-term), animal models (normal or genetically modified), animal type (rat, mice, monkey, or rabbits), animal age (young, adult, or old), animal strain, species (human or animal), gender (male or female), screening tissues (in vivo or in vitro), drug potency (low or high), and drug structural formula.

\section{CONCLUSION}

Six-week administration of CQP revealed occurrence of severe detrimental effects on the reproductive system of adult rats. Therefore, much more attention should be paid to CQP drug as a possible cause of male contraceptive and infertility especially when prescribed for long period of time or used in high daily doses to treat various diseases in children and adult male individuals. On the contrary, HCS is much less toxic than CQP to a great extent with a very low risk of orchidotoxic effects that may replace therapy with CQP. Also, assessment of male reproductive functions should be done periodically for patients receiving both drugs, especially $\mathrm{CQP}$, for prolonged time as they commonly encountered with endocrine disruption.

\section{REFERENCES}

Abolghasemi, E. , Moosa-Kazemi, S. H. , Davoudi, M. , Reisi, A. , and Satvat, M. T. (2012): Comparative study of chloroquine and quinine on malaria rodents and their effects on the mouse testis. Asian Pac J Trop Biomed, 2:311-314.

Adeeko, A. O. Dada, O. A. (1994):Chloroquine excretion in semen following antimalarial-drug administration. Andrologia, 26:165166.

Adeeko, A. O. and Dada, O. A. (1998): Chloroquine reduces fertilizing capacity of epididymaspermin rats. Afr J Med MedSci, 27:63-64.
Adjene, J. O. and Adenowo, T. K. (2005): Effects of chronic administration of chloroquine on the weight of the intracranial auditory relay centers of adult wistar rats. JMBR, 4:70-74.

Aparicio, I. M. , Espino, J. , Bejarano, I. , Gallardo-Soler, A. , Campo, M. L. , Salido, G. M. , Pariente, J. A. , Peña, F. J. , and Tapia, J. A. (2016): Autophagy-related proteins are functionally active in human spermatozoa and may be involved in the regulation of cell survival and motility. Sci Rep, 16:6:33647.

Asuquo, O. R. , Igiri, A. O. , Olawoyin, O. O. , and Eyong, E. U. (2007): Correlation of histological and histometric changes in rats testes treated with chloroquine phosphate. Niger J PhysiolSci, 22:135-139.

Bearden, H. J. and Fuquay, J. W. \{Eds. \} (2000): Semen evaluation. In: Applied Animal Reproduction. Prentice Hall, Upper Saddle River, New Jersey, pp: 168-182.

Ben-Chetrit, E. , Tischel, R. , Hinz, B. , and Levy, M. (2005): The effects of colchicine and hydroxychloroquine on the cyclo-oxygenases COX-1 and COX-2. RheumatolInt, 25:332-335.

Clewell, R. A. , Pluta, L., Thomas, R. S. , and Andersen, M. E. (2009): In utero exposure to chloroquine alters sexual development in the male fetal rat. ToxicolApplPharmacol, 237:366374.

Creasy, D. M. (2001): Pathogenesis of male reproductive toxicity. ToxicolPathol, 29:64-76.

D'Cruz, O. J. and Uckun, F. M. (2000): Vanadocene-mediated in vivo male germ cell apoptosis. ToxicolApplPharmacol, 166:186-195.

De Kretser, D. M. and Holstein, A. F. (1976): Testicular biopsy and abnormal germ cells. In: The Human 
Semen and Fertility Regulation in Men (Hafez, E. S. E. ed). Mosby Co. , St. Louis, Missouri, pp: 332-343.

Desai, K. R. , Dattani, J. J. , Rajput, D. K. , Moid, N. , Highland, H. N. , and George, L. B. (2012):Role of curcumin on chloroquine phosphateinduced reproductive toxicity. Drug ChemToxicol, 35:184-191.

Didolkar, A. K. and Sundaram, K. (1989): Mechanism of LHRHStimulated Steroidogenesis in Rat Leydig Cells: Lipoxygenase Products of Arachidonic Acid May Not Be Involved. J Androl, 10:449-455.

Ebong, P. E. , Eyong, E. U. , Eteng, M. U. and Ukwe, C. W. (1999): Influence of chronic administration of chloroquine on Leydig cell integrity and testosterone profile of albino Wistar rats. Afr J Reprod Health, 3:97-101.

Egbunike, G. N. (1982):Effect of chloroquine on the motility and acetylcholinesterase activity of porcine spermatozoa during epididymal maturation. Andrologia, 14:503-508.

Ejebe, D. E. , Ojieh, A. E. , Ovuakporaye, S. I. , OdionObomhense, H. K. , Adegor, E. C. , Amadi, C. N. , Nwadito, C. , Emudainohwo, J. O. T. , and Ozoko, T. C. (2008): Effects of antimalarial alkaloids on the sperm properties and blood levels of reproductive hormones of adult men. Afr J Biotechnol, 7:3395-3400.

Ekaluo, U. B. , Udokpoh, A. E. , Ikpeme, E. V., and Peter, E. U. (2008): Effect of chloroquine treatments on sperm count and weight of testes in male rats. Global Journal of Pure and Applied Sciences, 14:175-177.

Eleftheriades, E. G. , Ferguson, A. G. , Spragia, M. L. , and Samarel, A. M.
(1995):Prolyl hydroxylation regulates intracellular procollagen degradation in cultured rat cardiac fibroblasts. $\mathrm{J}$ Mol Cell Cardiol, 27:1459-1473.

El-Sharaky, A. S. , Newairy, A. A. , Elguindy, N. M. , and Elwafa, A. A. (2010):Spermatotoxicity, biochemical changes and histological alteration induced by gossypol in testicular and hepatic tissues of male rats. Food ChemToxicol, 48:3354-3361.

Farombi, E. O. , Adedara, I. A. , Abolaji, A. O. , Anamelechi, J. P. , and Sangodele, J. O. (2014):Sperm characteristics, antioxidant status and hormonal profile in rats treated with artemisinin. Andrologia, 46:893-901.

Farombi, E. O. , Ekor, M. , Adedara, I. A. , Tonwe, K. E. , Ojujoh, T. O. , and Oyeyemi, $M$. O. (2012):Quercetin protects against testicular toxicity induced by chronic administration of therapeutic dose of quinine sulfate in rats. $\mathrm{J}$ Basic ClinPhysiolPharmacol, 23:39-44.

Fitch, C. D. and Russell, N. V. (2006): Accelerated denaturation of hemoglobin and the antimalarial action of chloroquine. Antimicrob Agents Chemother, 50:2415-2419.

Gaafar, K. M. , Khedr, M. I. , Bashandy, S. A. , Sharaf, O. A. , and el-Zayat, S. R. (2002):Effect of chloroquine on glucose metabolism. Arzneimittelforschung, 52:400-406.

Gamble, M. and Wilson, I. (2002): The Hematoxylins and Eosin. In: Theory and practice of histologial techniques. Bancroft JD, Gamble M, (Eds). $5^{\text {th }}$ ed. Philadelphia, PA: Churchill Livinsgtone, Elsevier, pp: 125-138.

\section{GeamănuPancă, A. , Popa-} Cherecheanu, A. , Marinescu, B. , Geamănu, C. D. , and Voinea, L. M. (2014): Retinal toxicity associated with chronic exposure to hydroxychloroquine and its ocular 
screening. Review. J Med Life, 7:322326.

Grunewald, S. , Paasch, U. , and Glander, H. J. (2007): Systemic dermatological treatment with relevance for male fertility. J DtschDermatolGes, 5:15-21.

Gumińska, A. , Slowikowska-Hilczer, J. , Kuzański, W. , Sosnowski, M. , Oszukowska, E. , Marchlewska, K. , Walczak-Jedrzejowska, R. , Niedzielski, J. , and Kula, K. (2007): Features of impaired seminiferous tubule differentiation are associated with germ cell neoplasia in adult men surgically treated in childhood because of cryptorchidism. Folia HistochemCytobiol, 45:S163168.

Hargreaves, C. A. , Rogers, S. , Hills, F. , Rahman, F. , Howell, R. J. , and Homa, S. T. (1998): Effects of cotrimoxazole, erythromycin, amoxycillin, tetracycline and chloroquine on sperm function in vitro. Hum Reprod, 13:1878-1886.

Hsuah, A. J. W. , Weish, J. H. , and Johns, P. B. C. (1981): Inhibition of ovarian and testicular steriodogensis by epidermal growth factor. Endocrin, 108:2002-2004.

Izunya, A. M. , Nwaopara, A. O. , Aigbiremolen, A. and Oaikhena, G. A. (2010): Body and testicular weight changes in adult Wistar rats following oral administration of artesunate. Research Journal of Applied Sciences, Engineering and Technology, 2:302-306.

Jones, M. L. (2002): Connective tissues and stains. In: Theory and practice of histologial techniques. Bancroft JD, Gamble M, (Eds). $\quad 5^{\text {th }}$ ed. Philadelphia, PA: Churchill Livinsgtone, Elsevier, pp: 139-162.

Katewa, S. D. and Katyare, S. S. (2005):Antimalarials inhibit human erythrocyte

membrane acetylcholinesterase.

ChemToxicol, 28:467-482.

Drug

Korte, D. W. Jr. , Heiffer, M. H. , Hacker, M. P. , Kintner, L. D. , Hong, C. B. , and Lee, C. C. (1979):Subchronic toxicity of the antimalarial drug, mefloquine hydrochloride (WR-142,490), in monkeys and dogs. Fed Proc Fed Am SocExpBiol, 38:680.

Lanning, L. L. , Creasy, D. M. , Chapin, R. E. , Mann, P. C. , Barlow, N. J. , Regan, K. S. , and Goodman, D. G. (2002): Recommended approaches for the evaluation of testicular and epididymal toxicity. ToxicolPathol, 30:507-20.

Liu, S. , Chen, S. , Li, M. , Zhang, B. , Shen, P. , Liu, P. , Zheng, D. , Chen, Y. , and Jiang, J. (2016): Autophagy activation attenuates angiotensin IIinduced cardiac fibrosis. Arch BiochemBiophys, 590:37-47.

Mackenzie, A. H. (1983): Pharmacologic actions of 4-aminoquinoline compounds. Am J Med, 75:1-7.

Magwere, T. , Naik, Y. S. , and Hasler, J. A. (1997): Effects of chloroquine treatment on antioxidant enzymes in rat liver and kidney. Free RadicBiol Med, 22:321-327.

Mbajiorgu, E. F. , Aire, T. A. , Volk, W. , and Albert, M. (2008): Low protein diet enhanced the toxicity of combined ethanol and chloroquine administration on gonadal weight, seminiferous tubular diameter and epithelial height of male SpragueDawley rats: A morphometric study. IJHS, 1:120-126.

McChesney, E. W. (1983): Animal toxicity and pharmacokinetics of hydroxychloroquinesulphate. Am J Med, 75:11-18.

Millong, G. (1961): A modified procedure for lead staining of thin 
sections. J BiophysBiochemCytol, 11:736-739.

Mok, C. C. and Lau, C. S. (2000):Profile of sex hormones in male patients with systemic lupus erythematosus. Lupus, 9:252-257.

MSDS (Material Safety Data Sheet) (2011):Hydroxychloroquine sulfate, Toxicological Information. Product Number: H0915, CAS-No. 747-36-4, EC-No. 212-019-3. Sigma-Aldrich, 3050 Spruce Street, Saint Louis, MO 63103, USA, pp:1-5.

Nduka, E. U. and Dada, O. A. (1984): Effect of acute chloroquine treatment on prostaglandin- and gonadotropinstimulated testosterone secretion of rat testis. ToxicolLett, 23:315-320.

Nduka, E. U. and Dada, O. A. (1987): Effect of chronic chloroquine treatment on prostaglandin and human chorionic gonadotropin (hCG) stimulation of testosterone secretion by the rat testis. Andrologia, 19:561564.

Nicola, W. G. , Khayria, M. I. , and Osfor, M. M. (1997):Plasma testosterone level and the male genital system after chloroquine therapy. Boll Chim Farm, 136:39-43.

Niu, Y. R. , Wei, B. , Chen, B. , Xu, L. H. , Jing, X. , Peng, C. L. , and Ma, T. Z. (2016): Amodiaquine-induced reproductive toxicity in adult male rats. MolReprodDev, 83:174-182.

Norman, C. and Gombe, S. (1975):Stimulatory effect of the lysosomal stabilizer, chloroquine, on the respiration and motility of fresh and aged bovine spermatozoa. J ReprodFertil, 44:481-486.

Obianime, A. W. and Aprioku, J. S. (2009): Comparative study of artesunate, ACTs and their combinants on the hormonal parameters of the male guinea pig. Niger J PhysiolSci, 24:101-106.
Oforah, E. , Idang, B. J. , and Kalu, N. (2004): Chronic chloroquine administration causes low circulating plasma testosterone and low luteinizing hormone associated with testicular lesion in rat. Acta PharmTurcica, 46:141-147.

Okanlawon, A. O. and Ashiru, O. A. (1998):Sterological estimation of seminiferous tubular dysfunction in chloroquine treated rats. Afr $\mathrm{J}$ Med MedSci, 27:101-106.

Okanlawon, A. O. , Noronha, C. , Sanyaolu, A. and Ashiru, O. A. (1990): Chronic effects of chloroquine on the morphology of the interstitial space in rat testis. Eur $\mathbf{J}$ Pharmacol, 183:1754.

Okanlawon, A. O. , Noronha, C. C. , and Ashiru, O. A. (1993): An investigation into the effects of chloroquine on fertility of male rats. West Afr J Med, 12:118-121.

Olumide, S. A. and Raji, Y. (2011): Long-term administration of artesunate induces reproductive toxicity in male rats. J ReprodInfertil, 12:249-260.

Osinubi, A. A. , Ajala, M. O. , Noronha, C. C. , and Okanlawon, A. O. (2006):Quinine lowers serum and testicular testosterone in adult Sprague-Dawley rats. Afr J Med MedSci, 35:425-430.

Ostensen, M. (2006): [Antirheumatic therapy and reproduction. The influence on fertility, pregnancy and breast feeding]. Z Rheumatol, 65:217220, 222-224.

Østensen, M. , Khamashta, M. , Lockshin, M. , Parke, A. , Brucato, A. , Carp, H. , Doria, A. , Rai, R. , Meroni, P. , Cetin, I. , Derksen, R. , Branch, W. , Motta, M. , Gordon, C. , Ruiz-Irastorza, G. , Spinillo, A. , Friedman, D. , Cimaz, R. , Czeizel, A. , Piette, J. C., Cervera, R., 
Levy, R. A. Clementi, M. , De Carolis, S. , Petri, M. , Shoenfeld, Y. , Faden, D. , Valesini, G. , and Tincani, A. (2006): Antiinflammatory and immunosuppressive drugs and reproduction. Arthritis Res Ther, 8:209,1-19.

Pareek, A. , Yeole, P. G. , Tenpe, C. R. , Chandurkar, N., and Payghan, R. (2009):Effect of atorvastatin and hydroxychloroquine combination on blood glucose in alloxan-induced diabetic rats. Indian $\mathrm{J}$ Pharmacol, 41:125-128.

Pasadhika, S. and Fishman, G. A. (2010): Effects of chronic exposure to hydroxychloroquine or chloroquine on inner retinal structures. Eye (Lond), 24: 340-346.

Pile, K. , Graham, G. G. , Katelaris, C. H. , and Day, R. O. (2016): Antimalarial drugs. In: Compendium of Inflammatory Diseases. Parnham M. J. (Ed. ). Springer, Switzerland, pp. 97-101.

Rainsford, K. D. , Parke, A. L. , Clifford-Rashotte, M. , and Kean, W. F. (2015): Therapy and pharmacological properties of hydroxychloroquine and chloroquine in treatment of systemic lupus erythematosus, rheumatoid arthritis and related diseases. Inflammopharmacology, 23:231-269.

\section{Rodriguez-Caruncho, C. and} BielsaMarsol, I. (2014): Antimalarials in dermatology: mechanism of action, indications, and side effects. ActasDermosifiliogr, 105:243-252.

Sairam, M. R. (1978): Drug effects on lutropin action. In: Structure and Function of the Gonadotropins. McKerns, K. W. (ed). Plenum Press, New York, p. 275.
Salman, T. M. and Ajayi, O. P. (2007): Ascorbic acid and alpha-tocopherol ameliorate chloroquine-induced impairment of sperm motility and viability in male rats. Trop J Health Sci, 14:9-12.

Salman, T. M. , Olayaki, L. O. , Shittu, S. T. , and Bamgboye, S. O. (2010): Serum testosterone concentration in chloroquine-treated rats: effects of ascorbic acid and alpha-tocopherol. Afr J Biotechnol, 9:4278-4281.

Silva, C. A. , Bonfa, E. , and Østensen, M. (2010): Maintenance of fertility in patients with rheumatic diseases needing antiinflammatory and immunosuppressive drugs. Arthritis Care Res (Hoboken), 62:1682-1690.

Smith, E. P. , Lu, L. , Chernausek, S. D. , and Klein, D. J. (1994):Insulin-like growth factor-binding protein-3 (IGFBP-3) concentration in rat Sertoli cell-conditioned medium is regulated by a pathway involving association of IGFBP-3 with cell surface proteoglycans. Endocrinology, 135:359-364.

Taherian, E. , Rao, A. , Malemud, C. J. , and Askari, A. D. (2013): The biological and clinical activity of antimalarial drugs in autoimmune disorders. CurrRheumatol Rev, 9:4562.

Tanenbaum, L. and Tuffanelli, D. L. (1980): Antimalarial agents: chloroquine, hydroxychloroquine, and quinacrine. Arch Dermatol, 116:587591.

Totty, B. (2002): Mucins. In: Theory and practice of histologial techniques. Bancroft JD, Gamble M, (Eds). $5^{\text {th }}$ ed. Philadelphia, PA: Churchill Livinsgtone, Elsevier, pp: 163-200.

Trifunac, N. P. and Berstein, G. S. (1982):Inhibition of the metabolism and motility of human spermatozoa 
by various alkaloids. Contraception, 25:69-87.

Walum, E. (1998): Acute oral toxicity. Alternative Testing Methodologies. Environ. Health Perspect, 106:497503.

Wu, G. L. , Wu, N. Y. , Li, T. Y. , Fan, Y. S. , Yu, G. Y., and Lu, W. W. (2015):Effect of Chinese herbal medicines for nourishing yin, supplementing qi, and activating blood on reproductive endocrine activity and immune functions in patients with primary Sjogren's syndrome. Chin J Integr Med, 21:778-783. 


\title{
دراسة مقارنة لتسمم الخصى بين فوسفات الكلوروكين وكبريتات الهياروكسي

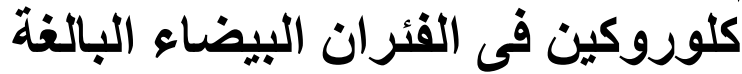

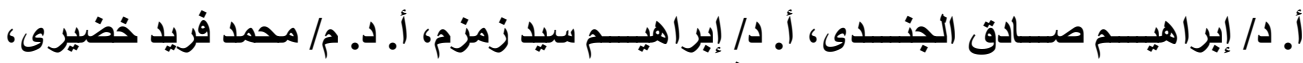

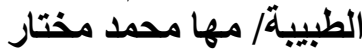 \\ قسم الطب الثرعى والسموم الإكلينيكية \\ كلية الطب - جامعة بنها والأكان
}

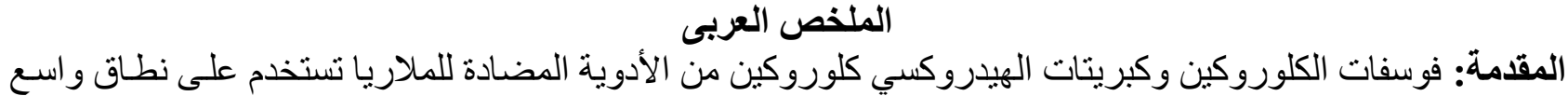

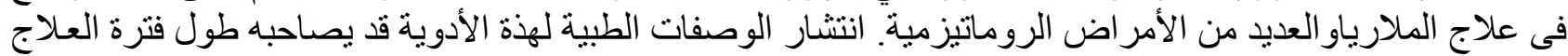

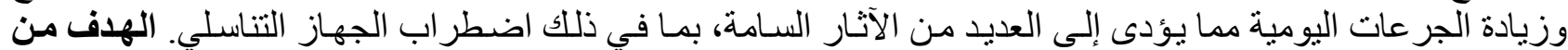

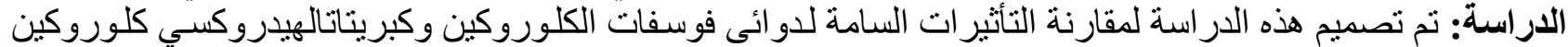

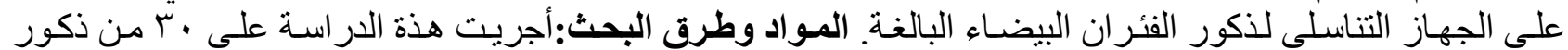

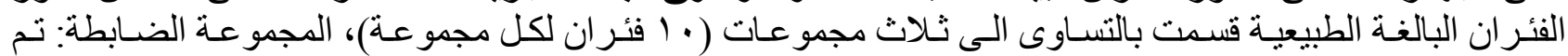

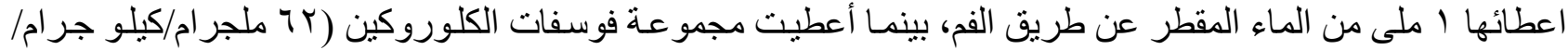

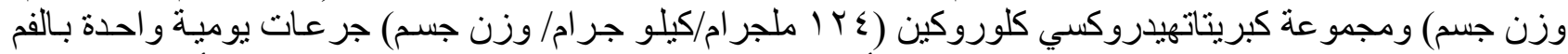

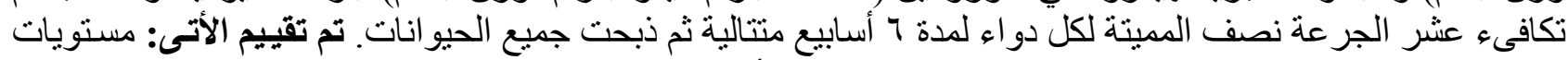

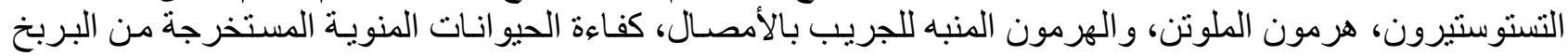

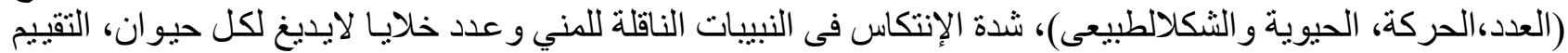

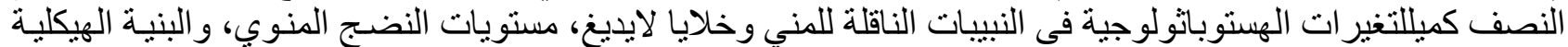

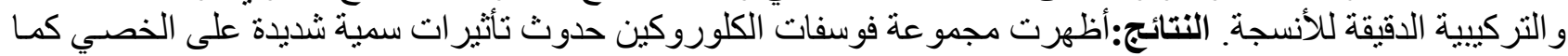

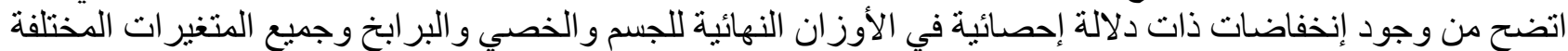

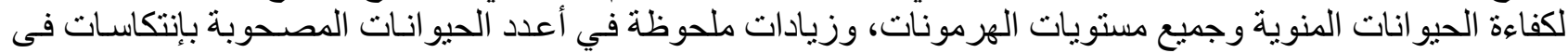

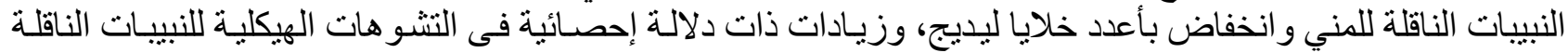

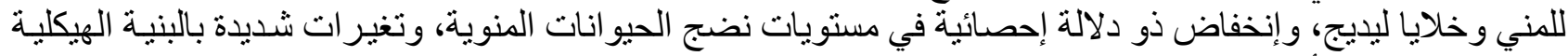

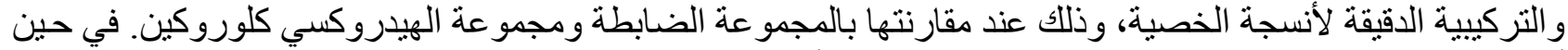

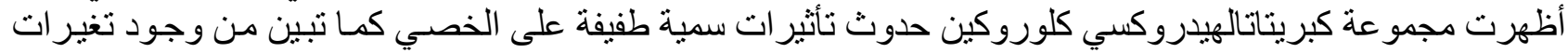

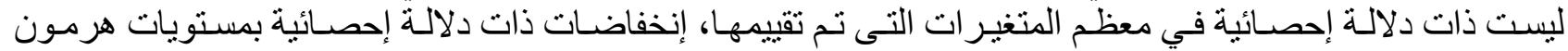

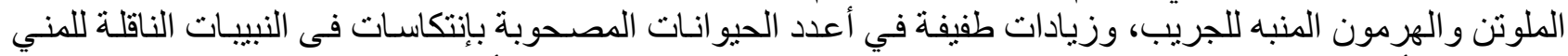

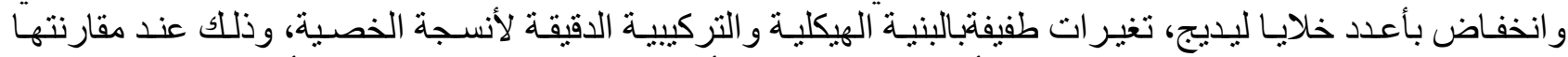

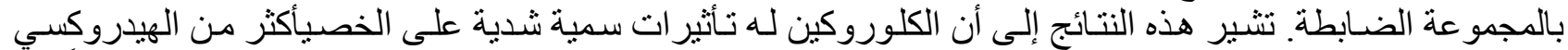

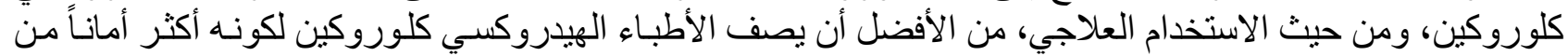

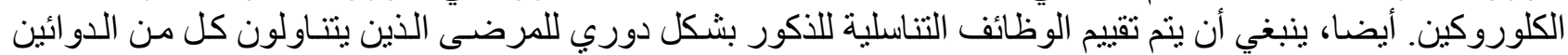

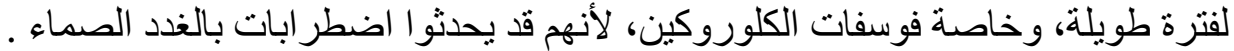

